\title{
What is Rhythmic Dissonance?
}

\author{
Evan O. Adams ${ }^{1 *}$
}

\begin{abstract}
Rhythmic Dissonance is an underrated and understudied compositional device. While some theorists have attempted to codify and explain this phenomenon, the number of these individuals has been few, as have the number of explanations and explorations in this area. The author explores the precedents set by previous theorists in order to gain an understanding of the current state of rhythmic dissonance. Select irregularities and fallacies within these previous theories are exposed and a new theory is presented in order to expand on previous interpretations and provide new avenues of exploration. This is done through a close examination of the current and historical musical literature. For practicality, the author develops methods of theoretical analysis and compositional application. The author seeks not to provide a prescriptive means of application, but rather to present avenues of artistic development paved by the exploration and understanding of new and interesting concepts.
\end{abstract}

\section{Keywords}

Metric Dissonance - Meter - Rhythm - Music Composition

${ }^{1}$ College of Music, University of North Texas

${ }^{\star}$ Faculty Mentor: Dr. Joseph Klein

\section{Contents}

\section{Introduction}

1 Current Understandings and Definitions

1.1 Existing Analyses of Musical Compositions . . . . 3

1.2 Contemporary Composers on Rhythm and Time 4

2 Summary of Existing Literature

6

3 Methodology

4 Analysis: Rhythmic Dissonance

\section{6}

4.1 Metric ... . . . . . . . . . . . . . . . 8

4.2 Temporal . . . . . . . . . . . . . . . 9

4.3 Contextual . . . . . . . . . . . . . . . . . . . 11

4.4 Resolving Rhythmic Dissonances . . . . . . . . . 12

4.5 Rhythmic Counterpoint . . . . . . . . . . . . . . 13

4.6 Harmony v. Rhythm: A Caveat . . . . . . . . . . 13

4.7 Polyrhythm v. Polymeter . . . . . . . . . . . . . 13

5 Examples from the Literature

5.1 Simple Polyrhythm . . . . . . . . . . . . . . . . 14

5.2 Complex Polyrhythm . . . . . . . . . . . . 15

5.3 Polymeter . . . . . . . . . . . . . . . 17

5.4 Polytempo . . . . . . . . . . . . . . . . . . 18

5.5 Contextual . . . . . . . . . . . . . . . . . . . . 19

6 Conclusions

7 Final Thoughts

Author Biography

\section{Background}

While music theory has historically focused primarily on explaining and quantifying harmonic and melodic functions within tonal and atonal contexts, it appears that there has been a relatively small amount of literature written in an effort to explain rhythmic functions in music. One such subject that demands attention is the phenomenon of rhythmic dissonance. While there have been some attempts at analyzing and defining this term under the guise of "metric dissonance," the last study that took an in-depth look was conducted nearly 30 years ago. ${ }^{1}$ While metric dissonance is a type of rhythmic dissonance, this term only scratches the surface. In addition, several subsequent authors seem to use the term metric dissonance in ways that contradict this author's initial theory. As music continues to evolve, time dictates a re-evaluation and re-clarification of this topic. In this paper I seek to define and categorize rhythmic dissonances in a way that encompasses both historical and current compositional practices and methodologies. Most importantly, I intend to suggest methods in which the contemporary composer can practically and consciously apply this technique to their own work.

As the term implies, rhythmic dissonance refers to tension created through the rhythmic structures of a piece of music. The point of interest and disagreement is in how this is achieved: what must occur that causes these tensions? My current hypothesis builds upon the theories of Henry Cowell, who suggested that rhythm and harmony are part of the same phe-

\footnotetext{
${ }^{1}$ Krebs, Harald, 1987, Some extensions of the concepts of metrical consonance and dissonance, Journal of Music Theory 31 (1) (Spring): 99-120.
} 
nomenon, just taking place over vastly different time scales. ${ }^{2}$ Once this relationship is established, musical devices used in harmonic analysis and writing can also find application in rhythm, specifically the use of ratios in classifying intervals and harmonic structure. Concepts unique to rhythm may also be applied to the analysis of rhythmic dissonance. An understanding of this will allow composers to utilize rhythmic techniques more effectively, just as the study of counterpoint can aid their melodic writing. A study of the structure of many pieces of music will be required to either validate or refute this hypothesis.

As a note, a majority of the past research presented on this topic deals with the term "metric dissonance" rather that rhythmic dissonance. For the purposes of this paper, I will consider metric dissonance to be a form of rhythmic dissonance, and regard some of the concepts Harald Krebs discusses under this classification to belong to other classifications, which will be sorted out in the "Rhythmic Dissonance" section.

\section{Current Understandings and Definitions}

The term "metric dissonance" has been used by many theorists, with one of the first being Joseph Schillinger, who in his System of Musical Composition refers to "two against three" combinations as dissonant. ${ }^{3}$ These combinations are now commonly referred to as either "tuplets" if they appear alone or polyrhythms if they appear in combinations with differing rhythms. Curt Sachs also refers to metric dissonances in his historical overview of rhythm, Rhythm and Tempo. However, he makes no attempt to define the term. ${ }^{4}$ Both of these authors, while making substantial contributions in other areas, have not made much of an attempt to explain metric dissonance or rhythmic dissonance as single entities.

The author who seems to have contributed the most to the defining of this phenomenon is Harald Krebs, whose work is an extension of ideas presented by Maury Yeston's concept of rhythmic stratum, which is essentially a level of motion within a rhythmic scheme. These levels of motion are defined by a succession of like musical events occurring at regular time intervals. Yeston argues that meter is a combination and interaction of two levels of motion: the first is a slower level, which groups and defines the second, faster level. When the faster level's rate of motion is not a multiple of the slower level, Yeston states that the figure is rhythmically dissonant. ${ }^{5}$

Krebs modifies and expands upon Yeston's concepts by altering the terminology from rhythmic stratum to metric dissonance and renames the levels of motion as either a "pulse

\footnotetext{
${ }^{2}$ Cowell, Henry, New Musical Resources, (New York: Cambridge University Press, 1996).

${ }^{3}$ Schillinger, Joseph, "Theory of Rhythm," in The Schillinger System of Musical Composition, (New York: Da Capo Press, 1946), 1-95.

${ }^{4}$ Sachs, Curt, Rhythm and Tempo: A Study in Music History, (New York: Norton, 1953).

${ }^{5}$ Yeston, Maury, The Stratification of Musical Rhythm, (New Haven and London: Yale University Press, 1976).
}

level" or an "interpretive level"; the latter imposes a metrical interpretation on the former. The rate of change of the interpretive level is defined as its "cardinality," which is based upon the number of pulses between successions of levels. These cardinalities are labeled as "n-level," where n represents the number of pulses.

Krebs proposes that in order for metric dissonance to occur, at least three levels must be present: one pulse level and two conflicting interpretive levels. Krebs goes on to introduce two variants of metric dissonance, "type A" and "type B." Type A dissonances occur when two interpretive levels of differing cardinalities express themselves simultaneously, while type B dissonances occur when two interpretive levels of the same cardinality express themselves offset from one another. ${ }^{6}$ He finds various examples of this in the literature, and further explores this same topic in his book, Fantasy Pieces: Metrical Dissonance in the Music of Robert Schumann. ${ }^{7}$

Krebs provides a solid foundation for the term metric dissonance, though there are a few key points from which my own hypothesis differs. Krebs states in this paper that at least three levels are required for metric dissonance to occur, while I believe it is possible and common for it to occur with only two levels (or even one, which I consider a contextual dissonance), as will be discussed later. Krebs' definition relies on alignment and misalignment of clear metric levels, while I believe metric dissonance can appear under much more subtle contexts and can be dependent on listener perception as well as rhythmic analysis. Yeston's definition, while covering less of the big picture, is closer to my interpretation in that it requires only two levels for dissonance to occur, though his labeling of this dissonance diverges from my own hypothesis. Regardless, Krebs' study has provided the framework for many more theorists after him to explore metric dissonance in detail.

Peter Smith has conducted a study where he observed examples of Krebs' type B dissonances in works by Brahms. ${ }^{8}$ Similarly, Ryan McClelland identified examples of Krebs' dissonances in other Brahms pieces. However, McClelland adds a practical viewpoint by explaining how the metric dissonances work in tandem with the harmonic dissonances to create tension. ${ }^{9}$ These two authors, in these particular articles, do not necessarily expound upon Krebs' work, though they do demonstrate the analytical applications of his work. While there are several authors who do this, quite a few offer examples of metric dissonance that do not necessarily coincide with Krebs' theory.

\footnotetext{
${ }^{6}$ Krebs, Harald, 1987, Some extensions of the concepts of metrical consonance and dissonance, Journal of Music Theory 31 (1) (Spring): 99-120, http://www.jstor.org/stable/843547.

${ }^{7}$ Krebs, Harald, Fantasy Pieces: Metrical Dissonance in the Music of Robert Schumann, (New York: Oxford University Press, 1999).

${ }^{8}$ Smith, Peter H, 2001, Brahms and the shifting barline: Metric displacement and formal process in the trios with wind instruments, Brahms Studies 3 (01): 191.

${ }^{9}$ McClelland, Ryan, 2005, Tonal and rhythmic-metric process in Brahms's early C-minor scherzos, Intersections: Canadian Journal of Music 26 (1) (09): 123-47.
} 
In another article, McClelland actually analyzes Brahms' Piano Trio in C-minor, Op. 101 using the term metric dissonance, but in a way that contradicts Krebs' definition. Krebs states that at least three levels must be present for metric dissonance to occur in his original article; however McClelland applies the term to an instance where only two levels are present: the main melodic line and the underlying meter. This metric dissonance is given a particular name, "barline displacement." Rather than having separate levels contradicting each other, an entire metric system is moved over one beat, causing the expected downbeat and the real downbeat to contradict one another. ${ }^{10}$ The author cites Krebs at one point, stating the use of "subliminal dissonance," which occurs when all the musical features of a section establish one level, while the notated meter establishes the other, conflicting level. ${ }^{11}$ Here Krebs cedes his point of needing three levels, expanding the scope of his metric dissonances. An example of a subliminal dissonance is shown below. ${ }^{12}$

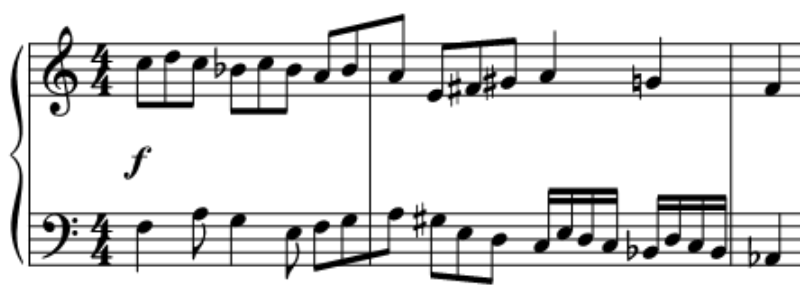

Figure 1. Subliminal Dissonance

In the previously mentioned article by McClelland, the key point of interest lies in the fact that even with a clear definition by Krebs, authors continue to offer varying accounts on what metric dissonance truly is. From a compositional standpoint, breaking of pre-established rules is appropriate and encouraged, but from a theoretical standpoint, consistency is the key to common understanding.

Samuel $\mathrm{Ng}$ provides a compelling dissection of hemiola and the hemiolic cycle, a well-studied phenomenon that creates metric dissonance using a completely different system than Krebs'. Ng makes use of beat classes, and defines what he calls "ON-n" states, with $n$ being the beat class of each measure. This system of ON-n states describes where the primary accents fall within a measure during a hemiolic cycle. In a measure of $3 / 4 \mathrm{ON}-1$ is a metrical consonance, and $\mathrm{ON}-2$ and $\mathrm{ON}-3$ are dissonances. A full hemiolic cycle in 3/4 goes ON-1, ON-3, ON-2, ON-1, which can be simplified to "1-3-21." This cycle can be augmented, with prolonged instances of an $\mathrm{ON}-2$ or ON-3 states creating metric tension. ${ }^{13}$

\footnotetext{
${ }^{10}$ McClelland, Ryan. 2006, Metric dissonance in Brahms's Piano Trio in C minor, Op. 101, Integral (20) (10): 1-42.

${ }^{11}$ Krebs, Harald, Fantasy Pieces: Metrical Dissonance in the Music of Robert Schumann, (New York: Oxford University Press, 1999).

${ }^{12}$ The author of this paper composed this example.

${ }^{13} \mathrm{Ng}$, Samuel, 2006, The hemiolic cycle and metric dissonance in the first movement of Brahms's cello sonata in F major, op. 99, Theory \& Practice 31 (10): 65-95.
}

Ng's system serves as a point of interest for two main reasons. First, it provides a cohesive way of organizing primary accents within a metric system. Secondly, and more importantly for my purpose, it describes a way in which metric dissonance can occur that does not rely on concepts provided by Krebs. Krebs is only referenced once in Ng's article, and only in passing. ${ }^{14}$ This does not mean that the two authors' methods are radically different. In fact, I believe them to be the same, just presented in different ways. I intend to clarify the discrepancies between the two systems, and create a method that explains and encompasses both.

While not directly related to rhythmic dissonance, Candace Brower has written on the idea of memory and perception, and how they can affect how we hear and perceive rhythmic figures within music. She describes the different types of memory we possess, with the relevant ones being echoic, short-term, and long-term. Echoic memory stores chunks of sensory information until they can be processed, short-term memory interprets the chunks and stores the perceived information, and long-term memory logically connects the chunks stored within short- term memory.

In regards to rhythm, Brower argues that we use all three types to perceive rhythmic patterns in a piece of music. Essentially, we hear small-scale rhythmic motives that are then processed in short-term memory, and only through the context of an entire passage do we understand each motive's relationship to one another through the use of long-term memory. Brower is arguing that listeners are innately capable of interpreting large-scale rhythmic structures within music by processing smaller structures first. ${ }^{15}$ While the relevance of this article may not be immediately clear, its potential use will become apparent when discussing the possible pitfalls of Henry Cowell's methods later in this paper.

Through an analysis of the current writings on the topics, it becomes clear that many methods of describing metric dissonance exist, although they do not always relate to each other in obvious ways. Some authors follow Krebs' methods, others stray in different directions. This obstructs any clear understanding of the topic and must be clarified in order to move forward with applications of the material.

\subsection{Existing Analyses of Musical Compositions}

In order for a musical phenomenon to have relevance in composition beyond the realm of pure theory, it must be either present within the historical compositional literature or manufactured with intent of applying it in future works. The phenomenon of rhythmic dissonance is present within the literature, and will continue to be used in the future, including my own works. Regarding the historical literature, I will show many examples of how rhythmic dissonance is used according

\footnotetext{
${ }^{14} \mathrm{Ng}$, Samuel, 2006, The hemiolic cycle and metric dissonance in the first movement of Brahms's cello sonata in F major, op. 99, Theory \& Practice 31 (10): 65-95.

${ }^{15}$ Brower, Candace. 1993. Memory and the perception of rhythm. Music Theory Spectrum 15 (1): 19-35.
} 
to my approach to this material; in the meantime, however, I will discuss the analysis done by other scholars.

As mentioned before, many theorists have studied and noticed what they call metric dissonance within the work of Brahms. Ryan McClelland notes that in the second movement of Brahms' Trio in C Minor, Op. 101 the "head motive" does not begin on a notated downbeat. In addition, the phrase length of this motive contradicts the notated meter. McClelland goes as far as to re-notate the section showing how the theme actually operates in relation to the underlying pulse. ${ }^{16}$

In another article, McClelland once again analyzes several pieces by Brahms, with a focus on his early $\mathrm{C}$-minor scherzos. Within these works, McClelland identifies several nested hemiolas and instances of barline displacement. He also notes that Brahms uses these devices to intensify tension created by the harmonic structure, leading to more gratifying resolutions. Peter Smith notes in his analysis of two of Brahms' trios for wind instruments, Horn Trio, op. 40 and Clarinet Trio, op. 114, that many examples of Harald Krebs' "type b" dissonances are present throughout the works. He, like McClelland, also notes that several of the phrases within the works contradict the notated meter by starting off of the downbeat. $^{17}$

All three of the previously mentioned articles focus heavily on metric ambiguity within Brahms' work, which excludes many other composers. Several of the other previously mentioned authors give examples of metric dissonance within other works, but they are mostly brief. Krebs notes several examples, citing Stravinsky, Webern, and many others, though he only provides short (approximately 8-bar) phrases for each. ${ }^{18}$ I am not suggesting that no other composers have been studied in-depth with the intent of finding metric dissonance; but the examples are limited. Samuel $\mathrm{Ng}$ provides an analysis of Beethoven's works, though he never directly states that his hemiolic cycle is a type of metric dissonance. ${ }^{19}$ Don Traut briefly discusses "metric displacement" in Stravinsky's works, but tends to focus on harmonic displacement more so than metric. ${ }^{20}$ Many more examples remain to be found in the literature of historical and current concert music, and should not be limited to the study of Brahms.

It is worth noting that authors have used the term metric dissonance not only to describe classical concert music, but also popular rock music. Nicole Biamonte provides several examples of how Krebs' dissonances are present within the music of Kansas, Black Sabbath, and similar Classic Rock

\footnotetext{
${ }^{16}$ McClelland, Ryan. 2006, Metric dissonance in Brahms's Piano Trio in C minor, Op. 101, Integral(20) (10): 1-42.

${ }^{17}$ McClelland, Ryan, 2005, Tonal and rhythmic-metric process in Brahms's early C-minor scherzos, Intersections: Canadian Journal of Music 26 (1) (09): 123-47.

${ }^{18}$ Krebs, Harald, 1987, Some extensions of the concepts of metrical consonance and dissonance, Journal of Music Theory 31 (1) (Spring): 99-120.

${ }^{19} \mathrm{Ng}$, Samuel, 2006, The hemiolic cycle and metric dissonance in the first movement of Brahms's cello sonata in F major, op. 99, Theory \& Practice 31 (10): 65-95.

${ }^{20}$ Traut, Don, 2007, More on displacement in Stravinsky: A response to van den Toorn. Musical Quarterly 90 (3) (Fall): 521-35.
}

artists. $^{21}$ This shows that metric dissonances can be used in a variety of contexts and gives credibility to the notion that many music creators have used variants of this technique intuitively in the past.

Overall, authors have observed some cases of metric dissonance within historical works; however there seems to be an oversaturation of Brahms. Furthermore, only Biamonte, and briefly McClelland, even discuss what musical and extramusical effects the use of these dissonances has on the listener. The other authors merely acknowledge their existence. Much remains to be found regarding metric dissonance, both theoretically and practically, and this paper seeks to address these ambiguities.

\subsection{Contemporary Composers on Rhythm and Time}

The previously mentioned articles are written from the perspective of the theorist. Thus, they are observations made post-composition using Krebs' existing theoretical groundwork. However, in addition to theorists, many composers have written on their ideas and techniques regarding rhythm. While few have explicitly written on the idea of metric dissonance, several have presented ideas that can be applied to or provide groundwork for Metric dissonance. These composers include the likes of Henry Cowell, Elliott Carter, and Gerard Grisey.

Elliott Carter, the composer famed for inventing metric modulation, makes note of the composer Roy Harris and his use of combining melodies with rhythms of differing and irregular stresses and cardinalities. Carter uses the term "crossaccented counterpoint" to describe this technique. ${ }^{22}$ While not mentioning it directly, this "cross-accented counterpoint" is essentially a form of metric dissonance. Multiple lines of differing cardinalities fall under Krebs' "type A" dissonance. This shows that composers of the 20th century were aware of the occurrence of layered, dissonant rhythms and their aural results. Even though Carter had described these dissonances in the past and coined a term for them, it has not appeared in any of the other consulted literature.

In addition to "cross-accented counterpoint," Carter also describes his use of layering multiple lines of varying, measured accelerando and ritardando and calls this technique "metric stratification." 23 In this specific instance he is considering changing tempos, however he also makes note of the works of Conlon Nancarrow and Charles Ives and their use of multiple fixed tempi. ${ }^{24}$ Both of these techniques involve the creation of rhythmic tension, and each composer uses it to provide independence to each musical line or group

\footnotetext{
${ }^{21}$ Biamonte, Nicole, 2014, Formal functions of metric dissonance in rock music, Music Theory Online 20 (2) (June, 2014): 19.

${ }^{22}$ Carter, Elliott, The Writings of Elliott Carter: An American Composer Looks at Modern Music, Compiled by Else Stone and Kurt Stone, (Don Mills, Ontario: Fitzhenry and Whiteside Limited, 1977), 160 - 166.

${ }^{23}$ Carter, Elliott, The Writings of Elliott Carter: An American Composer Looks at Modern Music, Compiled by Else Stone and Kurt Stone, (Don Mills, Ontario: Fitzhenry and Whiteside Limited, 1977), 243 - 247.

${ }^{24}$ Carter, Elliott, The Writings of Elliott Carter: An American Composer Looks at Modern Music, Compiled by Else Stone and Kurt Stone, (Don Mills, Ontario: Fitzhenry and Whiteside Limited, 1977), 160 - 166.
} 
of lines. While not explicitly referencing it, these two techniques are forms of temporal dissonances, named "fixed" and "malleable," respectively. This paper will cover these terms later.

Perhaps one of the most challenging aspects of defining rhythmic dissonance deals with the notion that singular rhythmic lines can be dissonant to the listener's ear by themselves. Within the realm of harmony, hearing a single note alone does not create any kind of harmonic tension. However, a lone $\mathrm{C} \#$ that directly follows a $\mathrm{C}$ major triad could sound dissonant due to the preceding context. Thus, not only can direct interactions cause dissonance, but also sudden changes from an established context. With this in mind, the question arises: how can you measure changes in metric structures in the same manner that you would harmonic structures? Gérard Grisey's thoughts on the organization of time begin to answer this question.

Grisey created a system of organizing temporal divisions on a scale of complexity, with one end representing predictability and order and the other zero predictability and disorder. He states that true periodicity, metric structures taking place in consistent amounts of time, represents order and predictability. These structures create an easily identifiable pattern, which could be considered true consonance. As one goes further down the scale, the level of predictability is diminished through the use of changing geometric and arithmetic functions that still retain patterns, but do not have recurring periodicities. Grisey argues that true chaos arises from statistical re-division of temporal durations that contain no traces of predictability. ${ }^{25}$

Ultimately, Grisey associates chaos with the lack of predictability. Rhythmic dissonance can be conceptualized as temporal chaos, thus the key to determining whether a single line is dissonant is its degree of predictability: the less predictable a line is, the more dissonant and vice versa. This establishes the importance of predictability, but alone it does not explain how to determine the degree of dissonance caused by the lack of predictability. However, combined with the methods introduced by Henry Cowell, which will be discussed shortly, a method of determining the degree of dissonance becomes apparent. This method relies on determining ratio relationships between subsequent temporal/metric durations.

Of all the composers mentioned so far, Henry Cowell and his views on rhythm coincide the closest with my own views on rhythmic dissonance. He relates the classification of rhythmic structures to the overtone series. With his methods, layers of different meters and polyrhythms can become "chords." Just as intervals in the harmonic series are determined by ratios of frequencies, the same can be done to rhythm. Thus, Cowell is arguing for the existence of rhythmic "intervals," which can be used as a starting point for determining degrees of dissonance.

The way Cowell treats polymeter and polyrhyhms vary

\footnotetext{
${ }^{25}$ Grisey, Gérard, 1987, Tempus ex machina: A composer's reflections on musical time, Contemporary Music Review 2 (1) (01/01): 239-57.
}

slightly, but they are essentially the same. Both deal with the periodicity of rhythmic figures; however polyrhythms are the result of multiplicative process while polymeters are an additive process. Polyrhythms' ratios are based on the number of one subdivision against another that takes place within a specific duration of time. For example, a quintuplet and triplet both taking place simultaneously within the space of 4 quarter notes (it should be noted the pulse level is not articulated in this instance) would have a ratio of 5:3.

Locating the point where all the meters realign and determining the number of cycles each meter goes through before realignment determines the ratios for polymeters. These ratios can be used as a method for determining intervallic qualities, as previously stated. As another example, two measures of $2 / 4$ can occur in the space of $4 / 4$, which is a ratio of $2: 1$ and correlates to an octave, the most consonant interval. Similarly, 2/4 and 4/4 fit together well, to the point of their combination being almost indistinguishable from the parts. This argument continues into different combinations of meters, such as 2/4 against $3 / 4$, which has a ratio of $3: 2$ and is equivalent to a perfect fifth.

With the comparison of rhythm to harmony comes the baggage associated with harmonic languages. Cowell introduces rhythmic counterpoint, which is the changing of one rhythmic ratio to another and is similar to harmonic counterpoint. To recall an example used previously, a quintuplet morphing into a triplet with a consistent four quarter-note pattern taking place under each figure would result in change from 5:4 to 3:4 and is reminiscent of second species counterpoint. ${ }^{26}$

In relation to Grisey's views on temporal divisions, perhaps an extension can be made applying Cowell's ratios to mixed meter as well. Thus, the horizontal ratios created by mixed meter would be as relevant as the vertical ratios of polymeter/rhythm. This phenomenon could be likened to the arpeggiation of chords: just as a major triad arpeggiated over a measure is still a major triad, any given polymetric "chord" could be "arpeggiated" through mixed meter. Cowell makes brief mention of this, but does not pursue the matter in much detail. $^{27}$ Grisey's method of predictability, or lack thereof, could then be quantified through the use Cowell's ratios. This type of rhythmic dissonance is called contextual dissonance.

With regard to Cowell's comparison of rhythm and meter to the harmonic overtone series, a problem of perception arises: can the classification and application of metric dissonance truly be derived from the current methods of interpreting harmony and pitch? While both deal with ratios of periodicity, harmony is perceived nearly instantaneously. While the sound and wavelengths do take time to express themselves, this time is incredibly fast and the human ear simply cannot interpret the process; it only can interpret the result. However with rhythm, because the amount of time

\footnotetext{
${ }^{26}$ Cowell, Henry, New Musical Resources, (New York: Cambridge University Press, 1996), 45-81.

${ }^{27}$ Cowell, Henry, New Musical Resources, (New York: Cambridge University Press, 1996), 77.
} 
needed to complete a full metric cycle (i.e. 3 measures of $2 / 4$ happening in the same space as 2 measures of 3/4) is significantly greater than that of pitch, more time is needed to simply gather all of the information necessary to process the metric dissonance/consonance.

Thus in the case of rhythm, it is the process rather than the result that the human ear experiences first and foremost. Due to the temporal nature of meter and rhythm, it could be argued that the ear cannot perceive large-scale, complex metric resultants at all, as the ear must constantly gather and process a continuous stream of new information with regard to rhythm. In this case, it may not be entirely possible to rely on definitions of pitch to formulate metric definitions. Brower's work on memory and perception may be able to validate some of these concerns.

Through the examination of various composers' thoughts on rhythm and time, it becomes increasingly clear that Krebs' definition of metric dissonance barely scratches the surface of the topic. Several ideas presented by the composers, such as Grisey's temporal divisions, are not addressed by Krebs' theory. Additionally, his "type A" dissonance is essentially an example of polymeter. He acknowledges its existence, but does not pursue methods of determining degrees of dissonance, nor does he seek to reveal its application potential. Both Grisey and Cowell provide qualitative and quantitative methods of describing dissonance through the use of predictability and numerical ratios. Conversely, the composers mentioned do not discuss the foundations of their metric principles as Krebs has and using existing literature (other than their own). A combination of both approaches is necessary to devise an effective method of analysis and application.

\section{Summary of Existing Literature}

Through analysis of recent studies on the topic of metric dissonance, a few trends have become evident. Krebs seems to be the most referenced author on the topic, and his ideas seem to be the most widely accepted. However, authors such as $\mathrm{Ng}$ give examples of metric dissonances that do not follow Krebs' ideas. While each of these authors presents valid ideas, there is no clear connection between the two other than the ending result of created tension. I believe these two methods of dissonances to be different variants of the same effect, and will provide evidence and concepts that support this theory. I seek not only to define rhythmic dissonance, but also to contribute to the way theorists and composers understand and interpret rhythmic structures within music.

Additionally, the writings of the various composers have provided another point of view regarding rhythm and time in general. Their work has shown the potential depth of this topic, and has also hinted at possible methods of application and even analysis. It has also shown the firsthand historical significance of metric dissonance, with Elliott Carter being fully aware of its existence even though he called it by another name. Ultimately, the writings of the composers have given a fresh point of view that contains many ideas that could provide a strong foundation for my proposed theory.

I currently have presented a foundation of theories and concepts regarding rhythmic dissonance, as well as a limited body of previously studied works. The next step is to expand and provide a clear definition and method of analysis for future works using examples from various works throughout history, as well as to discuss practical applications of these methods. While theory has historically been used as a means to describe composition rather than influence it, having an understanding of how previous composers structured their works can only aid in allowing the contemporary composer to express his/her ideas in an informed and effective context.

\section{Methodology}

In order to provide validation for my theory/definition of rhythmic dissonance, it will be necessary to study the existing music literature and find examples of this phenomenon of metric dissonance within the works. This study will focus on works written during the 20th and 21st centuries, with a few selections from other historical periods. It is a phenomenon that can be applied to current works; historical examples from notable composers support its validity and present new ideas for its application. In the event that no substantial examples exist, I will propose the adoption and implementation of my ideas into future works. Through the analysis of the literature, I will catalogue and develop ways in which metric dissonance can be applied to musical composition, as well as the musical effects it can have on the listener. The ultimate goal is to develop a method of analysis while avoiding a prescribed method of application, opting instead to demonstrate potential for development.

After gathering information from a multitude of resources and studies, I will formulate a theoretical system that identifies and groups varying types of rhythmic dissonances into different categories, each having different methods of application. These groups will include metric, temporal, and contextual dissonances. Through an exploration of the literature, I expect to find examples of these dissonances within several works of varying styles. It is from these works that I will derive and illustrate methods of historical application, while proposing some of my own.

Much like any creative endeavor I expect to find many exceptions to any rule I try to create, and this result is welcomed and encouraged. Through the exploration of unknowns, I hope to solidify and codify the understanding of rhythmic dissonance and its methods of analysis. I expect that, through the creation of an analytical method, various methods of application will become apparent. It is important to remember that rhythmic dissonance is not only a theory, but also a compositional technique.

\section{Analysis: Rhythmic Dissonance}

Rhythmic dissonance is the compositional tool of organizing and layering different qualities of rhythm (such as meter 
and tempo) to create tension within a piece of music. Different aspects of rhythmic dissonance have been discussed (sometimes under a different name) throughout the 20th and 21 st centuries; however I seek to organize these many ideas into a single theoretical concept. I will both compile existing theories/analyses and synthesize ideas of my own.

In order to begin categorizing rhythmic dissonances, a few premises must be stated. Firstly, when dealing with meter, rather than basing cardinal decisions on the time signature, I am instead opting to use phrase lengths. While at one point in history, the time signature may have defined the underlying metric structure, with the increasing complexity and innovation introduced within the last 100 or more years this may no longer be the case. One needs to only look at Stravinsky's L'Histoire Du Soldat to find many examples of consistent phrase lengths defying the cardinality implied by the time signature. This is not a strikingly new concept; several pieces of tonal music modulate to foreign key areas without explicitly marking a new key signature.

Secondly, in order to effectively utilize rhythmic dissonances from a compositional standpoint, one must be aware of how different variants compare to one another and the degree of dissonance a certain figure may have. To determine the degree of dissonance, I propose a system based on ratio relationships that are then compared to the overtone series.

Rhythm and harmony are essentially the same physical process, with the main difference being the timescale on which they operate. Both consist of impulses in a recurring pattern. Pitch results from the frequency of a sound wave, which is a periodic occurrence. Tempo is the steady repetition of consistent pulse. Thus, on a basic level, pitch and a marked tempo are the same process, and rubato and vibrato are analogous variations in this process. Karlheinz Stockhausen applies this concept beyond rhythm and even includes form and timbre, though this paper will prioritize the rhythmic aspects. ${ }^{28}$ This comparison extends into harmony.

Harmony, or chords, is made up of intervals, which are two or more frequencies that vibrate at a consistent ratio to one another. For example, the interval of a perfect fifth is made up of two frequencies that sound at a ratio of 3:2. Polyrhythms (and polymeter; see "Polyrhythm v. Polymeter") are made up of two rhythmic figures of differing cardinalities. In the case of a polyrhythm, in which a quarter note triplet sounds in the same amount of time as two quarter notes, the rhythmic ratio is $3: 2$. Thus, the ratio of the perfect fifth and the $3: 2$ polyrhythm are equivalent.

Henry Cowell asserted that these two processes, polyrhythms and intervals, are fundamentally the same. ${ }^{29}$ Though Cowell presented this idea many years before it could be realistically tested, new technology has allowed for the relationship between rhythm and harmony to be audible. ${ }^{30}$ Thus the overtone

\footnotetext{
${ }^{28}$ Stockhausen, Karlheinz, "How Time Passes By," Die Reihe Vol. 3 (1959): $10-40$.

${ }^{29}$ Cowell, Henry, New Musical Resources, (New York: Cambridge University Press, 1996), 46 - 48.

${ }^{30}$ Tepfer, Dan, "Rhythm/Pitch Duality: hear rhythm become
}

series can be used to describe rhythmic function as it does harmony. This bridge of reason allows existing harmonic concepts to be applied to rhythm.

Using David Cope's classification of interval strength, Paul Hindemith's ranking of intervallic dissonance, and the previously mentioned concepts, a system can be created to organize different ratios and their relative consonance and dissonance. ${ }^{31}$ What each ratio represents depends on the variant of dissonance in question. Figure 2 depicts the various intervallic ratios present in a diatonic scale represented on a number line. By observing the number line, one can see a pattern emerge. ${ }^{32}$

\begin{tabular}{|c|c|c|c|c|c|c|c|c|c|c|c|c|}
\hline & 1.11' & & & $1 . \%$ & & & 1.50 & & & & & 'נm! \\
\hline 告 & $1 / 1 / 1$ & 1615 19:8 & & 5 近 & 晃 & 25013 & $3 / 2$ & $8 / 3$ & 5 汿 & 9 & $15 / 8$ & $\overrightarrow{212}$ \\
\hline 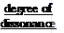 & 0 & & 0 & 4 & 3 & 12 & 2 & 5 & 7 & 9 & 11 & 1 \\
\hline intant & $\mathbf{v}$ & $\mathrm{m} 2 \mathbf{M} 2$ & $\mathrm{~m} 3$ & м3 & P4 & A4 $\quad \mathrm{d} 5$ & P5 & $\mathrm{m} 6$ & M6 & $\mathrm{m} 7$ & MT & PS \\
\hline
\end{tabular}

Figure 2. Chart of Intervallic Dissonance

The numbers directly below the ratio represent the degree of dissonance according to Hindemith (with modifications per Cope's ranking system to include the inversions of the root intervals), with 0 being most consonant, and 12 most dissonance. Beneath those numbers is the tonal interval label for each ratio. The tritone in just intonation has a different ratio depending on which tonal inversion the interval is in, however for the purposes of rhythm analysis, the degree of dissonance of these two may be considered equivalent.

When trying to determine the degree of dissonance of a certain ratio, compare it to Figure 2 . The closer in proximity it is to the lower partials of the overtone series, the more consonant (the lower partials have a lower degree number). The ratios marked on the graph are the most common ones, and correspond directly to the diatonic intervals. Ratios not already marked will fall somewhere in the spectrum depending on their numerical value, and can be compared to marked ratios to determine the degree of dissonance. The numerical value must be determined by dividing the smaller integer into the larger integer. If the result is greater than 2 , subtract one until the integer falls between 1 and 2; each subtraction of one is equal to an octave displacement.

pitch before your ears," last modified December 13, 2012, http://dantepfer.com/blog/?p=277.

${ }^{31}$ Cope, David, Techniques of the Contemporary Composer, (Belmont, CA: Schirmer Books, 1997), 40-41. Hindemith, Paul, The Craft of Musical Composition, (New York: Associated Music Publisher, 1941), 81. Hindemith's ranking system has been challenged since its conception, however it remains relevant to rhythmic dissonance. The main point of contention revolves around its source, which is the overtone series. The counter argument states that since equal temperament is the standard tuning system, and not just intonation (which stems from the overtone series), his assumptions are flawed (see Legname, "Density Degree of Intervals and Chords.") In the case of rhythm, tuning systems lose relevance due to the increased perception of time (see "Harmony... a Caveat").

${ }^{32}$ It should be noted that, according to Hindemith, intervals and their inversions retain the same degree of dissonance or consonance. According to Cope, the inversion that appears lowest in the overtone series should be more consonant; this interpretation is the one implemented into this paper. 
With these premises in mind, the 3 types of rhythmic dissonances will be explained below. These 3 types are metric, temporal, and contextual.

\subsection{Metric}

Metric dissonances occur when two or more meters (including polyrhythms) are superimposed over one another. There are two categories of metric dissonance: divisive \& displacement. $^{33}$

\section{Divisive}

Divisive dissonances occur when two or more meters of differing cardinalities occur simultaneously. After a set number of counts (depending on the internal cardinalities), all of the meters present will realign with one another. The name "divisive" stems from this quality: essentially, a set period of time is divided into several groups of opposing cardinalities. The two most common examples of this type of dissonance are polymeter and polyrhythm.

There are a few defining characteristics of this variant of dissonance that separate it from the others. Divisive dissonances periodically contain primary alignment points (P.A.), meaning all phrases align and begin at the same point in time. Figure 3 and Figure 4 demonstrate this phenomenon for both polyrhythm and polymeter, respectively. ${ }^{34}$

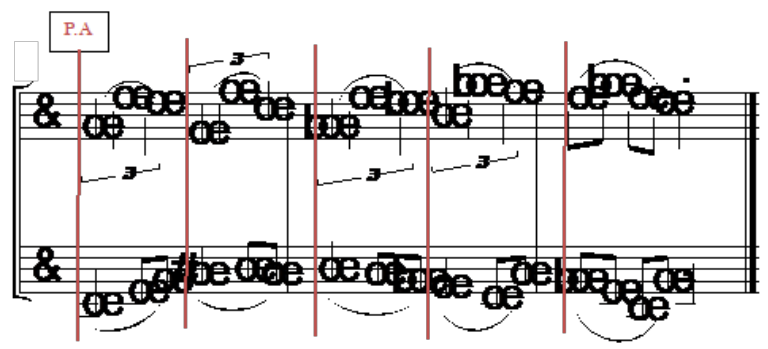

Figure 3. Example of Polyrhythm

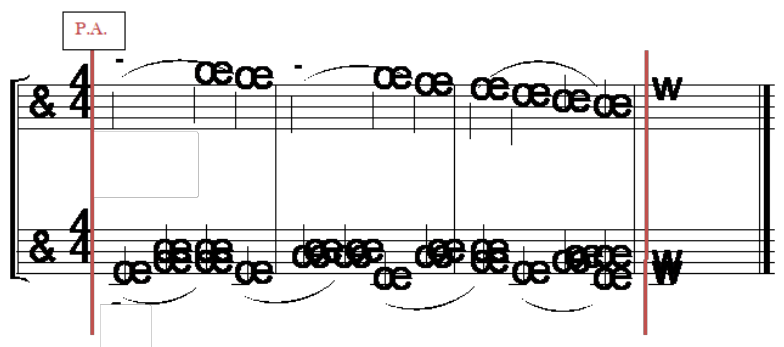

Figure 4. Example of Polymeter

Figure 3 is an example of a simple polyrhythm. In simple polyrhythms the cardinality of a tuplet and its phrase length match. In the case of complex extended polyrhythmic figures,

\footnotetext{
${ }^{33}$ Derived from Harald Krebs' theory of metric dissonance. "Divisive" dissonances correspond to Krebs" "type A" dissonance, and "displacement" corresponds to "type B."

${ }^{34}$ The author of this paper composed the musical examples in figures 3-8.
}

one or more of the tuplets may be phrased in a grouping that is not equal to the tuplet's cardinality. In these cases, incidental alignment points occur. Incidental alignment points (I.A.) are moments in time when two or more polyrhythmic figures begin in the same instant, without the phrases aligning. An example is shown in Figure 5.

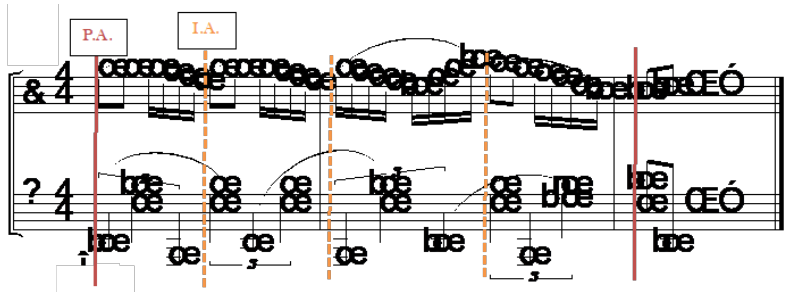

Figure 5. Example of Complex Polyrhythm

When considering the difference between primary and incidental alignment points with regard to polyrhythms, it is important to note the difference between tuplet cardinality and phrase length. In Figure 5, while the bass line contains almost exclusively triplets (with a cardinality of 3), they are grouped into phrases of 4 . Thus, while incidental alignment points occur every 2 beats, primary alignment points occur only in the first and third measures where the two phrases align.
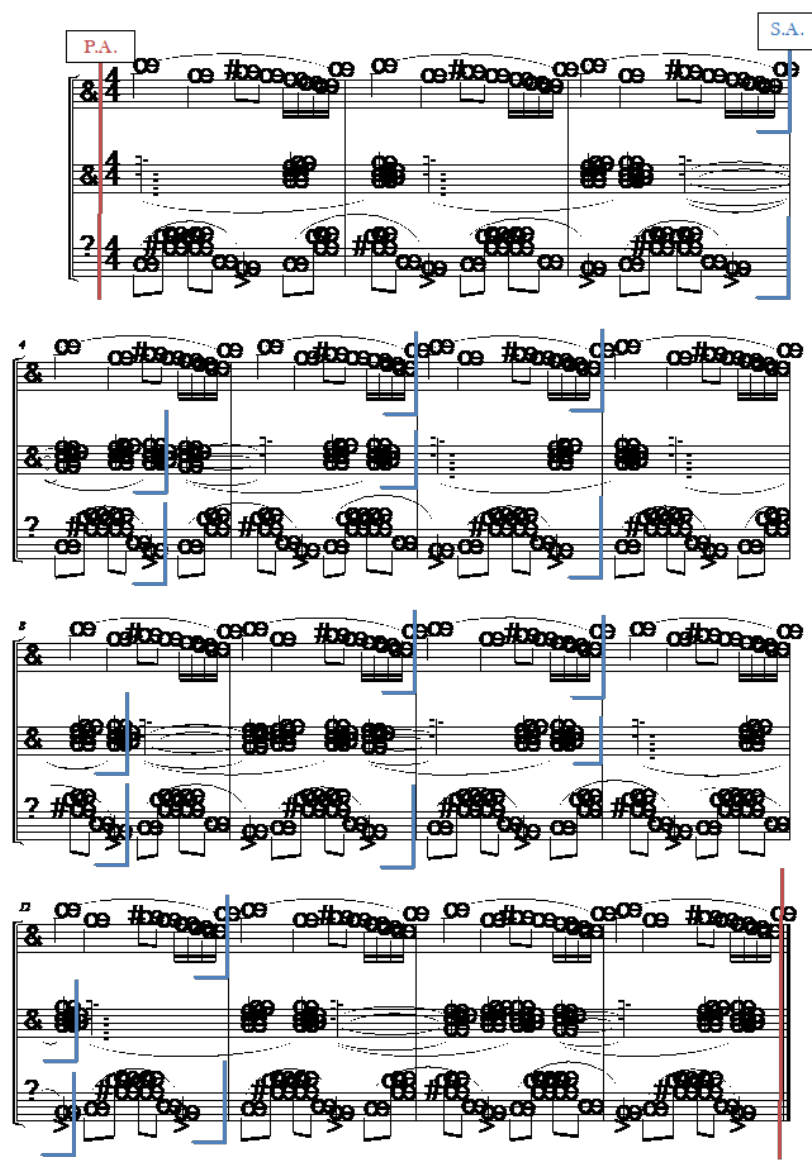

Figure 6. Secondary Alignment Points in Polymetric texture 
Polymetric and polyrhythmic structures, in addition to primary alignment points, may also contain secondary alignment points (S.A.) if three or more different phrase/tuplet lengths are present. Secondary alignment points occur when any number of phrases (aside from the total) aligns. These larger structures usually require a longer duration for a full cycle to be completed due to the nature of the rhythmic figure. Figure 6 and Figure 7 each show an example of secondary alignment points in a polymetric and polyrhythmic structure respectively.

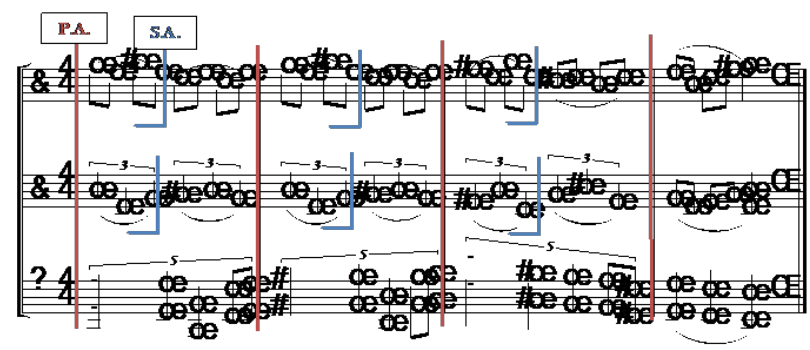

Figure 7. Secondary Alignment Points in a Polyrhythmic Texture

All three variants of alignment points provide varying degrees of stability within a metric structure, with primary alignment points being the most stable and incidental alignment points being the least. Secondary alignment points serve as an intermediary between the two; their occurrence is detectable by the ear, though due to some phrases still sounding out of sync, they are unable to overcome the overall texture and provide great stability. The more frequently alignment points occur (and in the case of secondary and incidental points, the larger the number of aligning phrases) the more that overall stability is present.

Cardinality, alignment points, and ratio relationships between different phrase lengths can be used to create a rhythmic structure that consciously utilizes rhythmic tension and guides the listener towards a total alignment point. This technique is considered divisive metric dissonance. This structure can then be analyzed using the tools previously mentioned. Figure 8 displays all of the concepts of divisive metric dissonance, along with a preview of a displacement dissonance.

\section{Displacement}

Displacement metric dissonances occur when two or more phrase lengths of the same cardinality occur offset from one another. These differ quite drastically from divisive dissonances in that they lack any alignment points. Unless at least one of the phrases changes cardinality, they will continue sounding offset infinitely. Canonic and fugal figures are common examples of displacement dissonances; however, they are far from the exclusive examples. Depending on the figure, this type of dissonance can sound like syncopation. In most circumstances, it is.

This paper will not attempt to expound upon divisive dis-
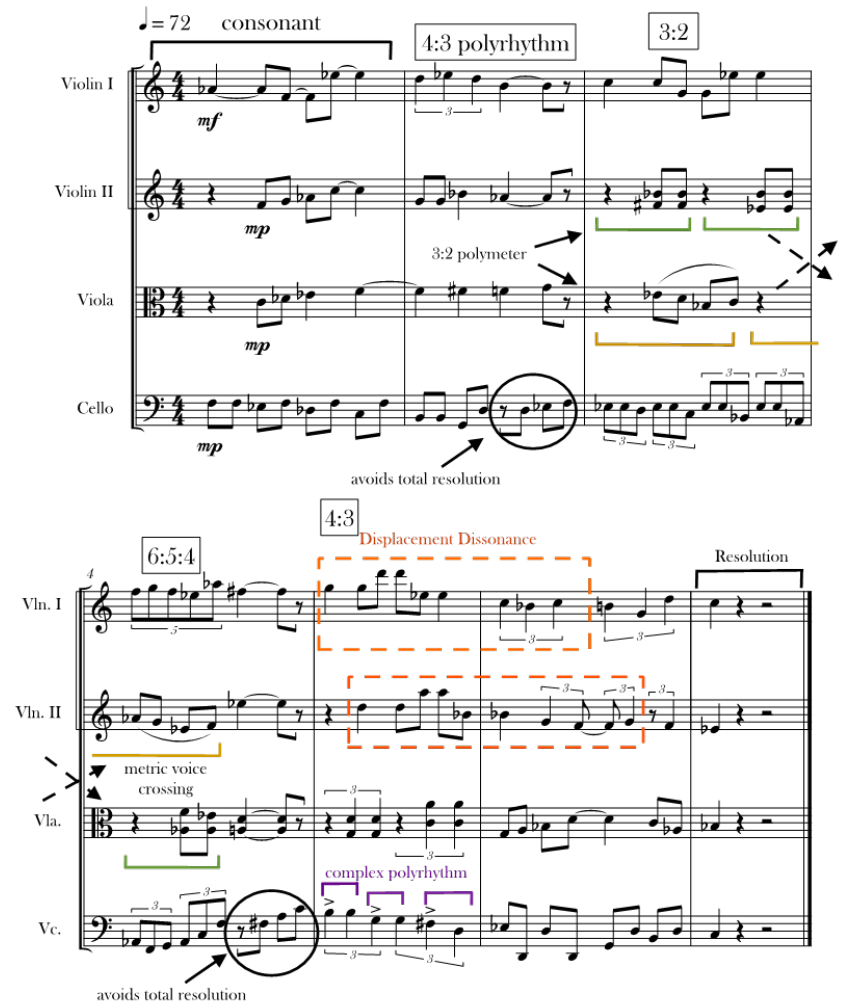

Figure 8. Metric Dissonance in Context

sonances. The nature of the occurrence diverts from the foundation established by Cowell and Grisey, so for the sake of brevity the topic will not be explored at present. Krebs' discussions on the subject go in depth and include a method of analysis for displacement dissonances. ${ }^{35}$ Compositional uses of the technique will be explored in later sections of this paper. My only contribution to this subject is its inclusion and classification within the rhythmic dissonance umbrella.

\subsection{Temporal}

Temporal dissonances occur when two lines of differing tempi occur simultaneously. These dissonances bear some similarities to divisive metric dissonances, as polyrhythms can be considered brief moments of polytemporal structures. Of all three rhythmic dissonance varieties, composers have historically used this technique the least. The list of composers who have explicitly used lines of varying tempi include the likes of the most avant garde and pioneering composers, such as Charles Ives and Conlon Nancarrow. ${ }^{36}$ It is the analysis of Nancarrow's work that has provided the foundation for temporal dissonance from a theoretical and compositional perspective.

While temporal and divisive metric dissonances have similar constructions, the two differ in a few key ways. Divi-

\footnotetext{
${ }^{35}$ Krebs, Harald, Fantasy Pieces: Metrical Dissonance in the Music of Robert Schumann, (New York: Oxford University Press, 1999), 33.

${ }^{36}$ es, Charles, Three Places in New England, Theodore Presser, 1935. Nancarrow, Conlon, Studies for Player Piano, 1948 - 1992
} 
sive dissonances contain phrases that have relatively frequent alignment points between the various phrases. Temporal dissonances do not emphasize the individual phrases that make up the distinct lines. Rather, the multiple tempi are considered on a much larger time scale, thus causing few alignment points. Divisive dissonances utilize small-scale, identifiable tensions, while temporal dissonances emphasize tension resulting over a larger period of time. Using terms presented in this paper, temporal dissonances will not contain primary or secondary alignment points over short amounts of time, while divisive metric dissonances do contain these points. The subjectivity of a "short" amount of time will be addressed in the "Examples from The Literature" section below.

Due to the popularity of Nancarrow's work among many contemporary figures, temporal dissonance - one of his most frequently used techniques-has received ample, thorough attention by theorists. The explanation and analysis techniques of Robert Wiley explain the technique with clarity, and his work is the model of this paper's explanation. ${ }^{37}$

The degree of dissonance of a polytemporal figure is dependent on the ratio relationship between the various lines. The numerical relationships can be compared to the chart in Figure 2 to determine relative dissonance to other ratios. As an example, a polytemporal figure with a tempo ratio of 3:2 would contain the tempi 90 and 60 . This figure would be relatively stable, but more dissonant than a figure with a tempo ratio of 2:1, containing the tempi 120 and 60 . Consonant polytemporal figures become clearer when the melodic materials are in canon, although the relationship is still present in non-canonic figures.

An important compositional quality inherent within temporal dissonances is the occurrence of convergence and divergence points. Convergence points are moments in time when two or more lines of differing tempi briefly realign with one another, either in passing or by coming to a close in the same instant. Divergence points are moments in time in which multiple lines of differing tempi begin together but then misalign over time. These two points can actually inhabit the same instance of time. The instant is considered a convergence point as it is approached, and becomes a divergence point as it passes into the past tense of time. This phenomenon is possible due to the linear way in which we perceive time.

Convergence points require occur most readily between two lines that contain the same number of beats, albeit at different tempi. Where the second voice must enter in relation to the first voice to create a convergence point depends on the ratio relationship between the two lines. If this relationship is $3: 2$, then the second, faster voice must enter $1 / 3$ of the way into the total length of the first, slower voice. As the second voice requires only $2 / 3$ of the time of the first to complete its statement, the placement of the entrance $1 / 3$ of the way into the first voice allows both end in the same instant, creating a

\footnotetext{
${ }^{37}$ Willey, Robert, "Electronic Realizations of Conlon Nancarrow's Study No. 37 for Player Piano," Last Modified 2003, http://willshare.com/willeyrk/creative/papers/study37/tempdiss.htm.
}

convergence point.

In order for a convergence point to occur, the second voice to enter must the quicker of the two. Otherwise, the entrance becomes a divergence point. The process of creating convergence points holds the same regardless of the dissonance of the ratio relationship and is replicated in the same manner as the above example.

Divergence points require much less planning and are more easily executed than convergence points. To create a divergence point, multiple lines of differing tempi must share an attack in the same point of time. These lines will naturally begin to drift apart from each other. The degree of dissonance relies on the ratio relationship between the varying tempi, as compared to Figure 2.

As mentioned previously, the same instance of time may be both a convergence and a divergence point. As an example, consider the earlier situation of two voices with a tempo ratio of 3:2. The faster voice enters $1 / 3$ of the way into the slower voice, which causes a convergence point in the instant that each voice's phrase ends. If the two voices were to not stop fully and continue to sound through the convergence point, that instant of time may be considered a divergence point as well, as the voices will begin to drift apart once again.

Convergence and divergence points serve as the ultimate tool for gauging temporal dissonances, as these points are where the dissonances either originate or terminate. Generically speaking, convergence points drive a musical figure from a state of dissonance to that of consonance, while divergence points do the reverse.

In order for convergence points to occur in non-canonic figures, the line of the quicker temporal state must contain a greater number of beats. The ratio of beats present in the quicker line versus that of the slower line may be determined through this temporal ratio. This would allow all of the lines to complete their cycles simultaneously. For a divergence point to occur, the lines must simply begin together.

In the event that one or more of the independent lines are also under the effect of an accelerando or ritardando, the point of interest, whether it be a convergence or divergence point, takes place when both lines share the same tempo. This moment may be brief, in which case it shifts from convergence to divergence as one tempo accelerates into the other and then begins to exceed it (or vice versa). This moment may also be extended, in which case one line reaches the tempo of the other and then ceases to accelerando or ritard. This resolution takes the structure from a state of temporal dissonance to consonance, making that point a convergence point. Lastly, multiple lines may begin with the same tempo and then slowly drift apart through an accel/rit, resulting in a divergence point.

The degree of dissonance in dynamic polytemporal figures (figures that include accelerandos and/or ritardandos) is much more abstract than in other forms of rhythmic dissonance. One method would be to use the ratio relationship between the starting and ending tempi of a specific line in relation to another, and compare the change. However, if one intends to 
compare two or more lines of changing tempo, determining a degree of dissonance becomes nearly impossible with human performers, as constant and exact rates of acceleration cannot be guaranteed. This effect may be possible with electronic compositions, though the practicality of such as an analytical tool falls short.

In dynamic polytemporal figures, the most reliable method of determining a degree of dissonance is the relative rate of acceleration of the line. Faster accelerations between two fixed tempo points gives less time for the listener to experience the dynamic polytemporal state, while more gradual accelerations give the listener more time. Thus slower acceleration rates yield more dissonant temporal states. In electronic music, the difference in accelerations can be exact; in acoustic music with human performers, these rates are much more difficult to achieve.

The addition of an accelerando or ritardano in a polytemporal figure adds another dimension to the overall structure. Not only is there dissonance between the fixed tempi, but the amount of time spent in a dynamic state also contributes to the overall dissonance of the figure.

\subsection{Contextual}

The previously mentioned variants of rhythmic dissonance rely on the sounding of at least two distinct metric or temporal layers. Contextual dissonances account for aural tension that arises from the method/pattern in which a single musical line is grouped. Referred to as indirect dissonances by Krebs, this tension stems from how our brains perceive and store memory. ${ }^{38}$

Gérard Grisey created a system of organizing temporal durations of events on a scale of order to disorder. ${ }^{39}$ This system is based on the degree of predictability of a pattern. The more predictable, the more orderly a pattern is. Low predictability correlates with chaos, which is disorder. While Grisey uses this system in reference to temporal durations (phrases measured in seconds) it can also be applied to rhythm, particularly the grouping of beats into macrostructures: meter. The more predictable a grouping pattern, the more consonant that metric line is.

Three factors can contribute to the overall dissonance level of a beat grouping. Symmetry of the metric grouping constitutes the first factor. Groupings that can be divided in equal halves without using subdivisions have a lower degree of dissonance than those that cannot be divided in half. For example, $4 / 4$ is divisible by two while $3 / 4$ is not.

Diversity of beat groupings constitutes a second factor. Metric structures with only a single grouping variant, such as 4/4 are relatively stable. Complex meters however, contain multiple variations of beat groupings, such as 5/8. Dissonance

\footnotetext{
${ }^{38}$ Krebs, Harald., Fantasy Pieces: Metrical Dissonance in the Music of Robert Schumann, (New York: Oxford University Press, 1999), 254. Brower, Candace, 1993. Memory and the perception of rhythm, Music Theory Spectrum 15 (1): 19-35.

${ }^{39}$ Grisey, Gérard, 1987, Tempus ex machina: A composer's reflections on musical time, Contemporary Music Review 2 (1) (01/01): 244.
}

increases with the number of unique beat groupings present, as this causes the degree of predictability to decrease.

Another factor is simply the number of beats that transpire before a pattern is established. Patterns comprised of shorter segments are easier to remember. ${ }^{40}$ The ease of memorization and predictability of these shorter segments allow them to sound more stable. As patterns become more complex and take a greater amount of time to establish themselves, they lose stability, which translates to an increase in perceived rhythmic dissonance. Patterns that require a smaller number of beats to complete a full cycle are more consonant, with the opposite being true for patterns with a greater number of beats. $^{41}$

All three factors affect the predictability of a given metric structure, which then affects the degree of dissonance. When taking these factors into account for determining the degree of dissonance, symmetry must be considered first, followed by beat variance and then cycle length. A measure of $10 / 8$ grouped $3+2+2+3$ is symmetrical, however a measure of $4 / 4$ is more consonant due to the lack of beat diversity. Similarly, even though $5 / 8$ requires fewer beats to establish its cycle than $4 / 4$, the latter remains more stable.

The previous three factors provide a fine level of gradation between degrees of dissonance. In addition, contextual dissonances can fall along a much larger consonance/dissonance spectrum with 3 major points, the most consonant point being true periodicity. Metric structures that are truly periodic consistently and predictably repeat a particular sequence. Any piece of music that contains a single time signature/phrase structure and does not deviate from it demonstrates true periodicity. The next point, which is more dissonant, contains metric structures that do not have a periodic sequence but still contain an identifiable pattern. This pattern may be constructed through any arithmetic or geometric function. Further tension may be added by consistently "skipping" outcomes in any given sequence. Aural repetition is absent, while repetition of process is mandatory. The last point, and most dissonant, is chaos. Chaotic metric structures have no clear periodic sequence, nor do they have any perceptible or imperceptible pattern or process of construction. This point provides no chance of predictability, and thus is rhythmically dissonant. ${ }^{42}$

These points lay on a spectrum; specific structures may fit somewhere in between two of the points. Additionally, two structures that both fall under a single category may project different levels of dissonance depending on the time needed to establish a period (if present) as well as the variety of beat groupings and symmetry of the figure. Figure 9 illustrates this contextual spectrum and Figure 10 shows several examples

\footnotetext{
${ }^{40}$ Brower, Candace, 1993. Memory and the perception of rhythm, Music Theory Spectrum 15 (1): 21-22.

${ }^{41}$ Beats are used as opposed to time, which would cause tempo to affect rhythmic stability.

${ }^{42}$ The three points are adapted from Grisey's order versus chaos graph. Some of his points are omitted entirely in this theory, as they lose relevance when considering specific metric and phrase structures rather than abstract temporal durations.
} 


\section{The Contextual Spectrum}

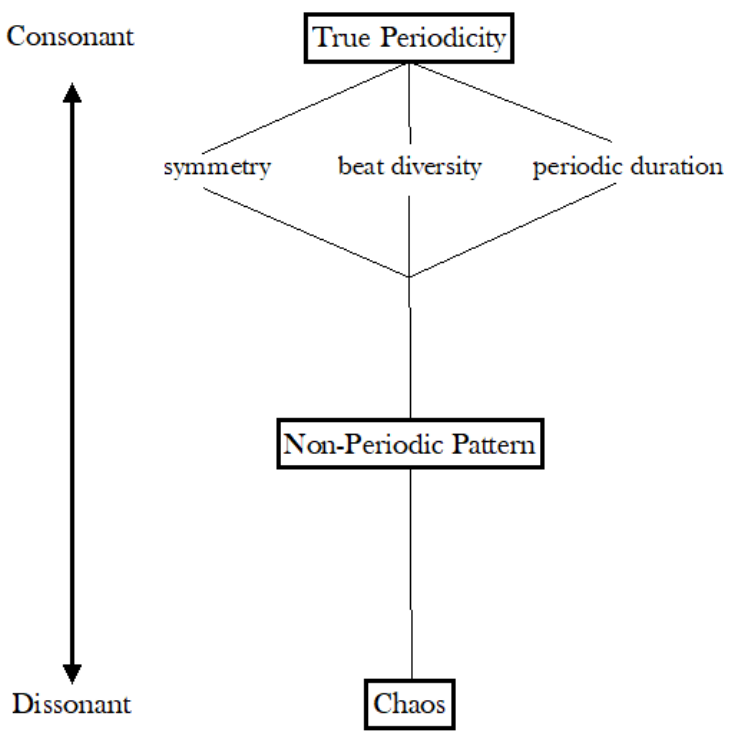

Figure 9. The Contextual Spectrum

of metric structures listed from most consonant (top) to most dissonant (bottom).

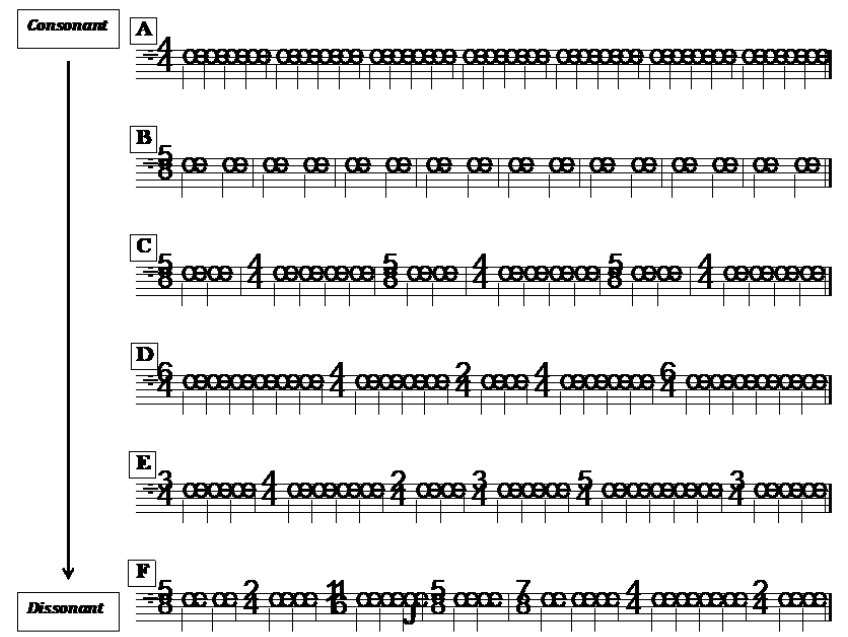

Figure 10. Tiers of Contextual Dissonances

Lines A, B, and $\mathrm{C}$ all demonstrate true periodicity; a repeating aural pattern is easily distinguishable. A contains only a single beat division, and is thus most consonant. $\mathrm{B}$ and $\mathrm{C}$ both contain two unique beat divisions, though $\mathrm{B}$ cycles through fewer beats than $\mathrm{C}$ before establishing its pattern, causing it to be more consonant.

Line D contains a process that features a recognizable arithmetic pattern. If $\mathrm{X}$ is the existing number of beats in a bar and $\mathrm{Y}$ is the new number, the function is $\mathrm{X}-2=\mathrm{Y}$.
Once the would-be output reaches 0 , the function inverts to $\mathrm{X}+2=\mathrm{Y}$. While the aural result alone may not provide a clear understanding of the pattern, it is wholly present in the process of creating the line. ${ }^{43}$

Lines $\mathrm{E}$ and $\mathrm{F}$ contain no discernable pattern. No functional process aided its construction and no perceptible pattern is expected of the listener. These two lines are among the most dissonant of the examples. Line $\mathrm{E}$ is considered more consonant due to the single beat division present, contrasting with the unique divisions of $\mathrm{F}$.

In addition to the spectrum adapted from Grisey, a method of analysis can also be derived using the rhythmic ratios in divisive dissonances. The vertical relationships between polymetric and polyrhythmic figures are comparable to the horizontal relationships between a succession of changing meters. A switch from $3 / 4$ to $4 / 4$ would have a ratio of $4: 3$, as 4 measures of $3 / 4$ take place in the space of 3 measures of $4 / 4$. When compared to harmony, this phenomenon is reminiscent of the relationship between chordal passages and arpeggiations; the intervallic relationships remain, but one takes place in an instant while the other is spread out over time. Henry Cowell discusses this in New Musical Resources. ${ }^{44}$ The use of ratios allows even more gradation to take place within the different levels of the contextual spectrum.

Within contextual dissonance analysis with ratios, two levels of time exist: these are the macro- and microlevels. Microlevels refer to changes of the division of the beat, such as triplets to eight notes and are comparable polyrhythmic analysis, while macrolevels refer to changes of meter, such as $4 / 4$ to $3 / 4$, and are comparable to polymetric analysis. Each is analyzed using ratios, as the relationship between the two is the same as the relationship between polymeter and polyrhythm.

\subsection{Resolving Rhythmic Dissonances}

Max Friedrich Meyer proposed that the finality of a progression from one melodic tone to another is determined by the ratio relationship between the two notes. Namely, moving towards the smaller number of the ratio produces a greater sense of finality, with this effect greatly increased if the smaller number is a power of 2 and the other is relatively small (such as 3). This is known as the Lipps-Meyer Law. ${ }^{45}$

This technique of finality is akin to resolving melodic lines based on intervals. This, like other harmonic techniques, can be applied to the realm of rhythm and offers possible means of resolving rhythmic dissonances in an informed manner. While Meyer only discusses the concept in the context of melodic intervals, it also applies to layered intervals, much in the same

\footnotetext{
${ }^{43}$ In this particular example, Grisey's concept of acceleration and deceleration of temporal durations is relevant. While the ear may not be able to pick up the arithmetic of the function, Grisey argues that the listener can perceive the steady decrease or increase of duration, which can affect the listener's perception of the section.

${ }^{44}$ Cowell, Henry, New Musical Resources, (New York: Cambridge University Press, 1996), 68 - 71.

${ }^{45}$ Meyer, Max F, The Musician's Arithmetic; Drill Problems for an Introduction to the Scientific Study of Musical Composition, (Columbia: The University of Missouri, 1929), 128.
} 
way that chordal implications remain regardless if a harmony is arpeggiated or sounded as a chord.

Rhythmic dissonances resolve when the layers of varying cardinalities converge into a single cardinality. This cardinality must be one that was previously present in the structure. The cardinality that the layers converge upon will determine the strength of the resolution; cardinalities whose ratio value is the smallest in a structure will be the most resolute, according to the Lipps-Meyer Law. Thus a cardinality of 1 is theoretically the strongest. This differs slightly from the Lipps-Meyer Law, as it does not account for unison resolutions. The same concept applies to contextual dissonances; the most resolute ending is one that ends on a smaller ratio value.

\subsection{Rhythmic Counterpoint}

Counterpoint as a musical idea may be defined as the juxtaposition of one or more voices against another. ${ }^{46}$ While this technique generally refers to harmonic and melodic materials, it can also apply to strictly rhythmic materials as well. By applying the definitions and classifications of rhythmic dissonance presented in this paper, creating and analyzing rhythmic counterpoint becomes as idiomatic as pitch-based counterpoint.

A composer may use a string of polyrhythmic figures to guide the listener from a state of consonance to a state of dissonance through the use of ratios and their relative degrees of dissonance. A polymetric structure may include a "ground bass" meter that remains constant while another voice changes meter multiple times, creating several different relationships between the two voices. The same phenomenon can be applied to polytemporal structures through independent tempo changes. Multiple rhythmic voices can be treated the same as they would in species counterpoint.

While the examples of metric and temporal dissonances shown in the previous section deal with static textures, more interesting ideas can be developed through the use of changing meters and tempos, which in turn creates contrapuntal movement. This provides an opportunity for conceptualizing a known musical variable in a new context.

\subsection{Harmony v. Rhythm: A Caveat}

The premise of this paper relies on the fundamental relationship between the phenomena of tempo and pitch. As theorized by Henry Cowell in the early 20th century and later proven through emerging technology, the overtone series and its translation to pitch and harmony also pertain to rhythm and tempo. This relationship supports nearly every rhythmic phenomenon discussed in this paper, as much of the terminology and concepts are, in essence, "borrowed" from the realm of harmony. While this may seem to imply that rhythm and pitch are capable of being examined in exactly the same context, this is not actually the case.

\footnotetext{
46 "Definition of Counterpoint," Merriam-Webster, accessed November 1, 2016, https://www.merriam-webster.com/dictionary/counterpoint.
}

The timescales in which humans experience rhythm and pitch differ greatly from one another. Pitch is perceived instantly. Rhythm is not. When a major chord is struck on a piano, 3 sound waves vibrate concurrently with a frequency ratio of 4:5:6. The human ear receives and interprets this information immediately, and the major chord sonority is experienced. However, if this same frequency ratio were to be applied to a polymetric structure, the full cycle would need 60 beats to come to completion; assuming a moderate tempo, this could take 45 - 85 seconds, which allows the listener to hear the inner relationships between the varying cardinalities. Thus, rhythm and pitch each create a unique aural experience. While both arise from the same mathematical process, pitch is perceived instantaneously as the final result of the process, whereas rhythm is perceived as the process itself unfolds.

Thus, while many concepts presented in this paper are derived from those of pitch, the relationship between the pitch and rhythm has limitations. Not all facets of one are completely applicable to the other. Restricting the analysis of rhythm to only methods used in harmonic analysis severely limits the potential of rhythmic dissonance. The difference in timescales allow for the inner machinations of rhythm (such as alignment points) to be perceived. The difference also negates certain intricacies inherent to harmonic practices, such as tuning systems. These fine attentions to detail, while incredibly important in the realm of pitch and harmony, lose relevance in rhythm simply because the ear cannot discern the differences.

Further experimentation in applying harmonic concepts to rhythm, such as melody, cadential patterns, and sequences, are encouraged. Applying these in a manner that allows listeners to experience the intended aural result may be a challenge, however. Pitch and rhythm result from the same process, but do not have the same aural effect due to the time-scale on which each is perceived.

\subsection{Polyrhythm v. Polymeter}

As mentioned in the previous section, an increased or decreased time-scale can have a significant effect on how a single process is interpreted. As a quick aside, it is interesting to note that this effect is present in the relationship between polyrhythm and polymeter. The following figure sets out to provide evidence that the two are the same process.

In Figure 10, A shows a simple 3:2 polyrhythm, the desired result of the proof. B shows a simple divided 3:2 polymeteric figure; for every three measures of $2 / 4$, there are two measures of 3/4. The first articulation of each measure has a natural metric accent, however a dynamic accent has been added for clarity of intent. This figure will be transformed into a 3:2 polyrhythm.

$\mathrm{C}$ shows the same polymetric figure, however the divisions of the beat have been removed, leaving only a single articulation per bar. Note that while this preserves the ratio relationship between events ( 3 notes from the bottom voice for every 2 from the top), the cardinality of each measure has 

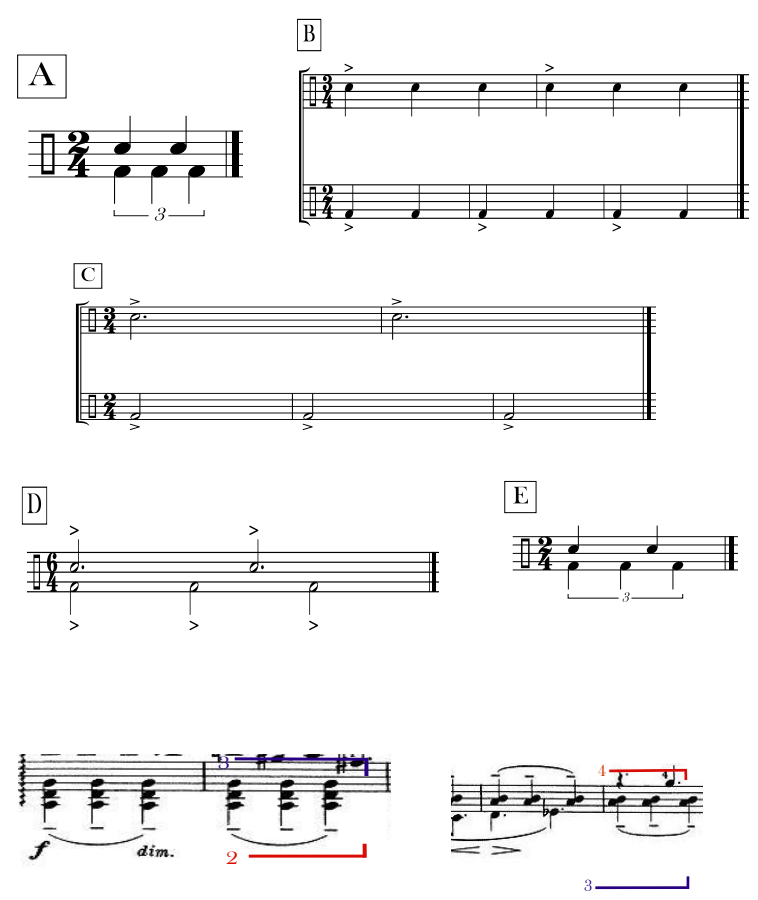

Figure 11. Transformation of Polymeter into Polyrhythm

become more ambiguous.

In $\mathrm{D}$, the two voices have been condensed onto a single staff, and the time signature has changed to account for the total duration of the figure. Both changes are only notational conveniences, as this figure will sound exactly like $\mathrm{C}$. The original ratio relationship between events remains unchanged.

In $\mathrm{E}$, the timescale of the polymetric figure has been reduced by a factor of $1 / 3$. The time signature has changed to reflect the new total duration, and the bottom voice has been re-notated to appear as a triplet. Again, these both are only notational conveniences. With an adjusted tempo, this new figure will resemble, and sound, exactly as A, the polyrhythm.

The previous figure demonstrates how a polymetric figure can be transformed into a polyrhythm, and also shows how the process of creation for the two is similar. The key difference is the time-scale on which the listener experiences the two. Additionally, when the divisions are removed from the original figure, the originating cardinalities of the measures are lost. This serves to accentuate the uniqueness of the two techniques, ultimately suggesting that polymetric structures are elongated, temporally expanded and subdivided polyrhythms.

\section{Examples from the Literature}

The concepts introduced in the previous chapter can be found in and applied to various works throughout history. However, this paper will mostly focus on works written in the 20th century or later.

\subsection{Simple Polyrhythm}

This variant of rhythmic dissonance is by far the most common, and appears frequently in works from the 20th century and later. A few simple examples, extracted from works by Igor Stravinsky and Benjamin Britten, are shown in Figure 11, with the ratio relationships outlined. ${ }^{47}$

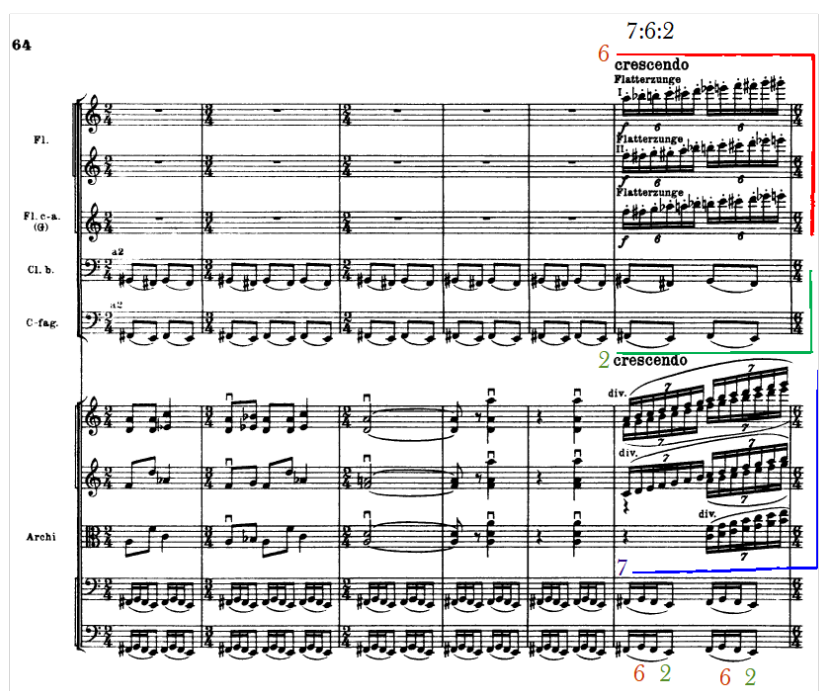

Figure 12. Igor Stravinsky: The Rite of Spring, "Ritual of the Two Rival Tribes"

By comparing the two examples, the difference of complexity can easily be quantified using ratios. Britten's Nocturnal utilizes a 3:2 polyrhythm towards the beginning of the work, which then develops into a 4:3 polyrhythm (Figure 11, bottom two panels). These two correspond to the perfect fifth and perfect fourth, respectively. As a quick aside, the dotted eighth notes in the 4:3 polyrhythm are phrased into groups of six, which mirror the accompaniment pattern, thus creating a polytemporal structure in addition to the polyrhythm. The Rite of Spring example contains a 7:6:2 polyrhythm, which has a higher interval density and complexity (Figure 13). Their ratios roughly correspond to a chord containing a M2, M6, and P5. This chord, when compared to the 4:3 and 3:2 in Nocturnal, sounds more dissonant due to its intervallic content; thus, the analogous rhythm sounds more dissonant as well.

The following excerpt from Charles Ives showcases rhythmic dissonance as a compositional tool to increase tension prior to the introduction of a new section.

Ives uses notated tuplet accelerandos with an ever-increasing degree of dissonance to drive the music forward. Beat 1 of the measure prior to $\mathrm{T}$ has a $3: 2$ rhythm, followed by a $4: 3: 1^{48}$,

\footnotetext{
${ }^{47}$ NOCTURNAL OP. 70, By Benjamin Britten Copyright 1963 (renewed) by Faber Music Limited. All Rights Reserved. International Copyright Secured. Used by permission. Stravinsky, Igor, The Rite of Spring (Dover Publications, 1989).

${ }^{48}$ The " 1 " in this case is displaced by an eight note, further increasing the tension.
} 


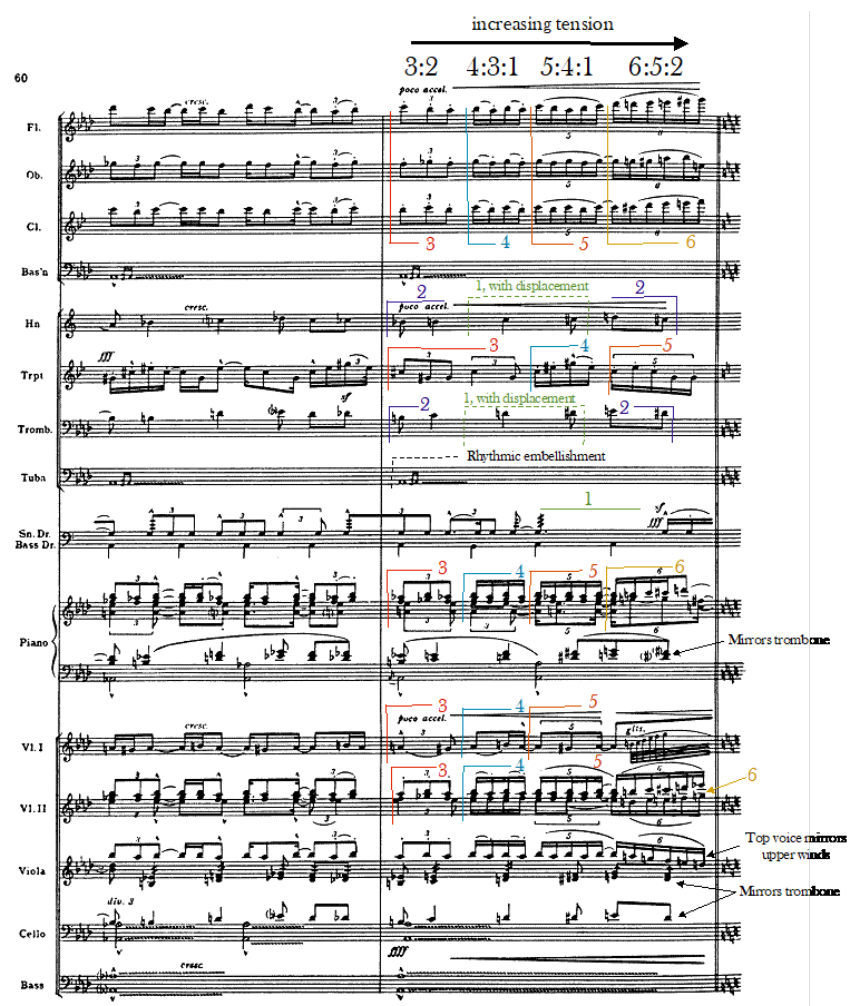

Figure 13. Charles Ives: Three Places in New England, "Putnam's Camp"

5:4:1, and 6:5:2. This translates into a P5, followed by a P4 + octave, M3 + octave, and $\mathrm{m} 6+\mathrm{P} 5+\mathrm{M} 3$. When referenced to Figure 2, the dissonance degrees thus read 2, 3, 4 in addition to the final beat containing multiple intervals with dissonance degrees of 5, 2, and 4. As shown using the system of ratio analysis and harmonic interval translation, the rhythmic tension increases during the transition, propelling the listener into the following section.

The final polyrhythm example is the entirety of Fabric by Henry Cowell. Compared to the examples shown thus far, this piece uses polyrhythms to a greater degree of finesse. For this work I have created what I call a Rhythmic Translation of the polyrhythmic structure. All of the ratios have been translated into intervals, and these intervals have been notated as a chorale texture. Each beat in this translation is a measure from the original piece. This translation clearly shows the consonance-dissonance relationship between the polyrhythms.

I arbitrarily assigned the " 5 " in the ratios to the pitch A3 (the actual pitch does not affect the outcome of the translation, as it is the intervallic relationships that are important here); the other pitches were determined relative to this pitch. For example, the first measure of Fabric features 3 voices: the soprano at 6 beats to the bar, the alto at 5 , and the bass at 8 . The ratio relationship of this polyrhythmic structure is $8: 6: 5$. Translated to pitch, this ratio is equivalent to a major chord in first inversion, as 5:6 is a minor third, and 8:6 is a perfect

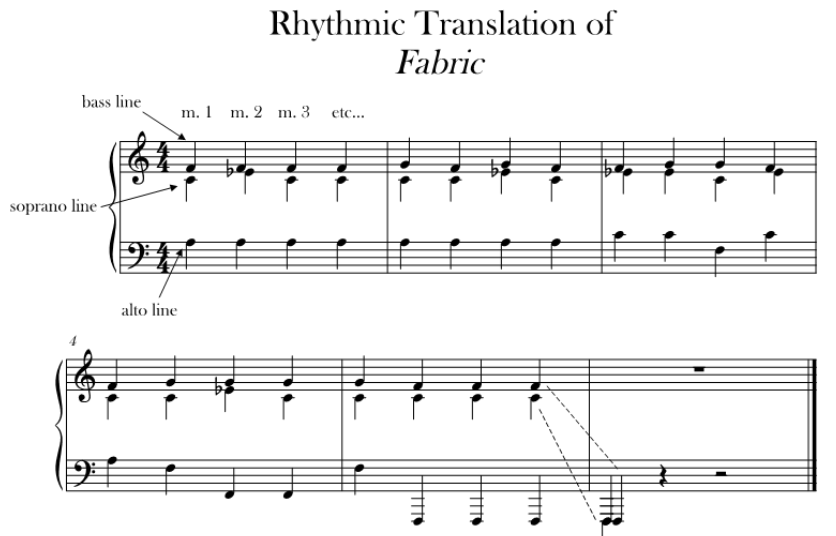

Figure 14. Cowell, Henry, Fabric (New York: Breitkopf \& Härtel, 1922)

fourth. Because the 5 is assigned to A3, the chord would thus be stacked A3, C4, F4. This is the first beat of the translation, which represents the first measure of Cowell's score; this method continues throughout the 21-measure piece.

Of particular interest within this translation is the third measure (representing mm. 9-12 of the original score). Prior to that point, the harmony has been relatively stagnant. The chord root changes from $\mathrm{F}$ to $\mathrm{C}$ in the 2 nd beat, and the outer beats have more closely stacked intervals including the $\mathrm{m} 3$, $\mathrm{M} 2$, and P4. When comparing this measure to the original score, we see that these few measures constitute the climax of the piece. The overall register reaches its highest point and sforzando dynamics appear in conjunction with crescendo and diminuendo markings. The most rhythmically complex moment of this piece appears during the climax.

The inverse is true as well: the final 2 measures of the translation show a drastic decrease in harmonic complexity, as the voices gradually shift from a quintal harmony to a root and fifth structure, and finally to a unison root. This decrease in complexity aligns with the ending of the original work. As the piece approaches its final cadential figure, the rhythmic complexity begins to decrease. As the degree of dissonance diminishes, the overall tension decreases with it, thus bringing the piece to a close.

\subsection{Complex Polyrhythm}

Complex polyrythms, over large spans of time, suggest polytemporal relationships. The distinction between polytempo and complex polyrhythms is somewhat subjective, due to the inability to quantify what is considered to be "large spans of time." Complex polyrhythms have frequently occuring secondary and/or primary alignment points, while lines of polytemporal relationships do not. Here again, what constitutes "frequently occuring" cannot be easily quantified, and is thus subject to interpretation. A similar situation in tonal harmony is exhibited in the interpretation of "pivot chords" within a modulating texture; theorists of differing opinions may disagree as to where the pivot chord occurs in a given 
tonal modulation.

The following examples bear the above caveat in their analysis. While I consider most of them to be examples of complex polyrhythms, I will also concede that they could be interpreted as polytempo. Some examples could convincingly be placed in either category, and I make note of this as well.

The first excerpt comes from Charles Ives' Three Places in New England during Putnam's Camp.

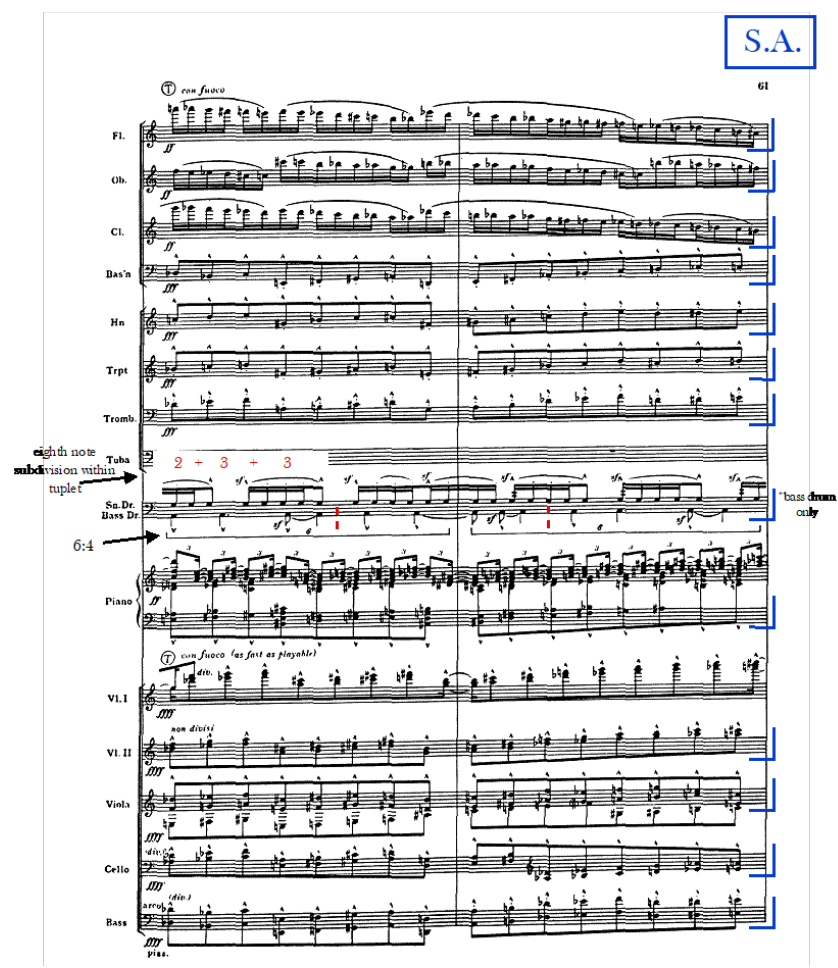

Figure 15. Charles Ives: Three Places in New England, "Putnam's Camp"

The bass drum's line at T contains a 6:4 polyrhythm, with six quarter notes taking the space of what would normally fill four. However the phrase within this polyrythm is broken into groups of four quarter notes with $2+3+3$ eight note subdivision. The phrase length of the line does not match the cardinality of the tuplet.

I consider this to be a complex polyrythm due to the occurence of secondary allignment points occuring two and four bars into the cycle. However, this example could be interpreted as a polytemporal figure, with the bass drum operating in a $4 / 4$ meter at $6 / 4$ ths the tempo of the other instruments. A primary alignment point occurs only at the end of the piece, at two bars after $\mathrm{U}$. This supports the polytemporal interpretation, as a true resolution occurs after a longer period of time. However, I believe the secondary alignment point is strong enough to warrant analysis as a complex polyrhythm, as only the snare drum, 1st violin, and the right hand of the piano fail to align at the alignment point two measures after $\mathrm{T}$.

An excerpt from Schnittke's Viola Concerto is shown below. ${ }^{49}$

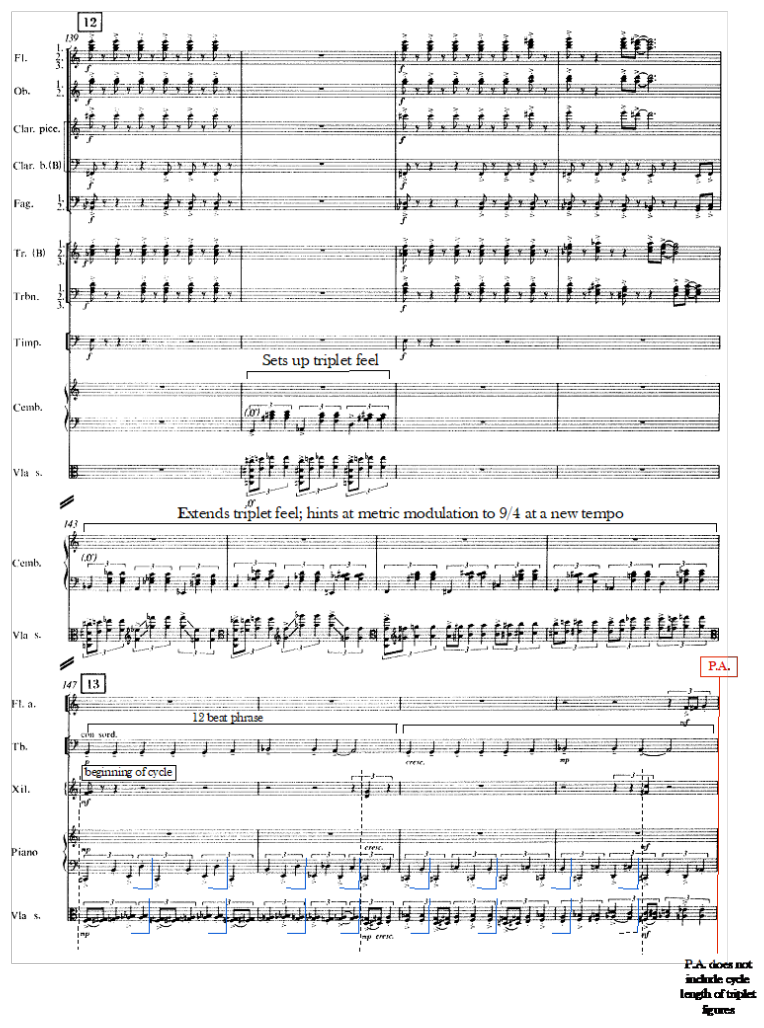

Figure 16. Alfred Schnittke: Concerto for Viola and Orchestra, 2nd Movement

Starting at 12, a series of contextual dissonances introduce the material that is explored at 13. At 13, the 3:2 triplet patterns are phrased into groups of four triplet quarter notes. These quarter note triplets are organized in cycles of 16, with the xylophone accenting the begining of each cycle. This line forms a dissonance with the trombone, which is playing a melodic figure in 6/4, with a constant phrasing of 12 quarter notes.

These two dissenting figures form an alignment point with respect to cardinality every 4 measures, which occurs frequently enough to consider this an example of a complex polyrhythm. The figures do not align with regard to overall phrase length, as the 16-note triplet cycles continue to overlap these points. The individual tuplet phrases align while the overall cycles do not, lending credence to the polytemporal argument.

In measure 157, a new texture with the same cycle length begins. Here the piano continues to play its phrase of 16 quarter-note triplets, which is mimicked by other voices such as the contrabass and harpsichord. The melodic figure, here carried by the trombones, continues in its established phrasing,

\footnotetext{
${ }^{49}$ CONCERTO FOR VIOLA AND ORCHESTRA By Alfred Schnittke Copyright (C) 1996 by Musikverlag Hans Sikorski International Copyright Secured. All Rights Reserved. Reprinted by Permission of G. Schirmer, Inc.
} 
while the sola viola begins to embellish and play outside the established rhythmic framework, thus disrupting the pattern. After two cycles of the new texture, a primary alignment point occurs at 14. This time, all of the voices resolve together in respect to cardinality and cycle length.

While alignment points occur relatively frequently, the total duration of the section lasts for a relatively long time. This prolonged exposure to contrasting phrases of differing tuplets could be interpreted as the triplet voices expressing a $4 / 4$ meter at 1.5 times the tempo of the melodic voices.

While the analysis is subjective, I believe these two examples exhibit complex polyrhythms rather than polytempo, due to the frequency with which secondary and primary allignment points occur. As will be demonstrated in the polytempo analysis section, works that I consider to be polytemporal contain much longer and more extreme instances of misalignment than those shown here.

\subsection{Polymeter}

The following examples (Figure 17) display instances of polymeter; some are implied while others are overt. The first example contains two excerpts from Jacques Hétu's Suite Pour Guitare, and is an example of implied polymeter.
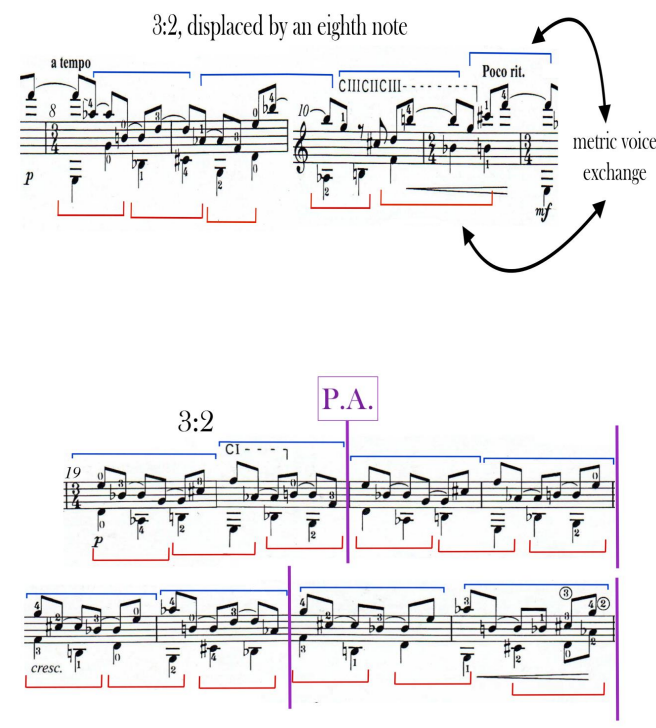

Figure 17. Jacques Hétu: Suite Pour Guitare, "Ballade"

The two voices are in 3:2 rhythmic counterpoint at the metric level with a displacement dissonance at measure 8 . I am interpreting the bottom voice as phrases of 2 due to the contour of the line, which implies a two-note grouping through its falling and rising action. Later at measure 19, a simple polymetric structure without a displacement occurs. This continues all the way through measure 26 , where the texture then resolves into a new section.

From a performance practice perspective, the duple bass groupings against the triple melodic figure could easily be masked. However, by emphasizing the underlying phrases of 2 , the performer can provide more expressive interest to this particular section. Without this conscious emphasis, the detail could easily be overlooked and performed as consonant $3: 3$ patterns. A rhythmic reduction of an excerpt from "Putnam's Camp" from Charles Ives' Three Places in New England is shown below.

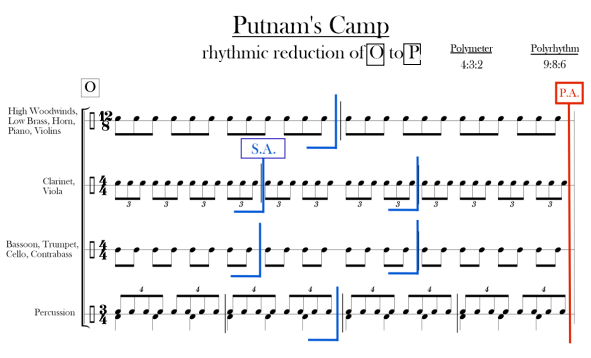

$=$

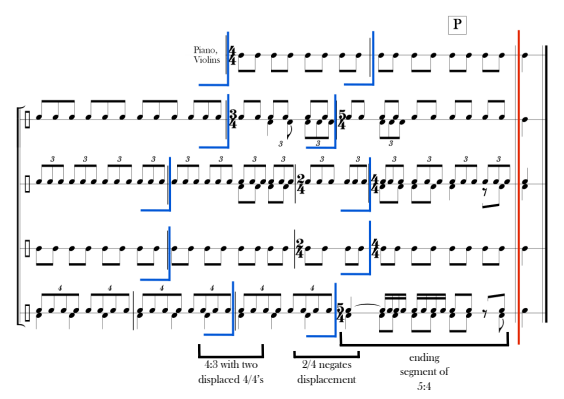

Figure 18. Rhythmic reduction of Charles Ives: Three Places in New England, "Putnam's Camp"

Of note within this example is how Ives changes the rhythmic harmony towards the end of the excerpt as he prepares a transition to a new section. The initial ratio relationship of 4:3:2 is expressed fully, and once the primary alignment point occurs, he begins shifting the phrase lengths around, which changes the expected points of resolution. Ives keeps the meters in a state of flux until just prior to $P$, where he ends with a relationship of 5:4. The degree of dissonance increases slightly over time until the final resolution.

As a brief aside, this example also features a 9:8:6 polyrhythm, which shifts to a $3: 2$ polyrhythm prior to the final resolution of the section. This represents a decrease in tension, which 
is in opposition to the polymetric figure. The example also implies a polytemporal relationship between the two upper voices of the reduction, and another between the two lower voices. This relationship is a 3:2 for both, and continues until the meters begin to change.

Overall this example showcases a wide scope of rhythmic dissonance techniques, and it is interesting to note how they all act to reinforce one another. It is the polymetric grouping of the polyrhythms that forms the polytemporal relationship; without the phrases grouped as they are, the example would simply be polyrhythmic.

The next example is taken from the first movement of Stravinsky's L'histoire du Soldat. As this example is much more complex than previous examples, two graphic reductions that show the various metric levels and how they interact with one another are included below.

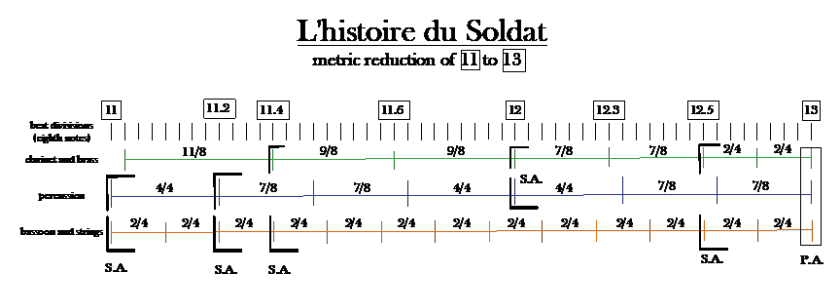

Figure 19. Igor Stravinsky: L'histoire du Soldat, "Soldier's March"

In addition to the alignment points represented on the above graphs, Stravinsky utilizes a metric ostinato to create rhythmic interest. The bassoon and strings maintain a $2 / 4$ meter while the other voices switch meters. This effect creates a sense of stability while the upper voices move in rhythmic counterpoint. This contrapuntal motion can be manipulated and altered in the same manner that one would vary melodic counterpoint.

Similar to the previous excerpt, this example, taken from Stravinsky's The Rite of Spring, is represented by a graph to show the relationship between voices. ${ }^{50}$

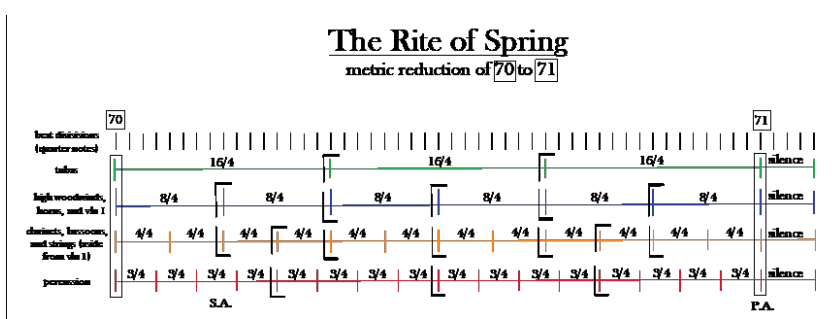

Figure 20. Igor Stravinsky: The Rite of Spring, "Procession of the Oldest and Wisest One"

Once the metric system begins there is no primary alignment point until the final measure of the section. Interestingly, rather than provide aural relief at this moment, Stravinsky chooses to punctuate the end of the system with silence, effectively denying the listener a resolution. The system creates

\footnotetext{
${ }^{50}$ Stravinsky, Igor, The Rite of Spring (Dover Publications, 1989).
}

a 3:6:12:16 tension at a climactic moment of the work, and avoids a resolution. In tonal harmony, pedaling a dominant harmony and ending the piece without a return to the tonic harmony would achieve a similar effect.

As stated previously, polymeter and polyrhythm share similar qualities but take place over different time-scales. Cowell, as mentioned, states that rhythm compressed into a shorter amount of time yields pitch. While the two are the same process, the perception and compositional use of each are vastly different. The difference in time-scale between polymeter and polyrhythm is a smaller gradation within this larger spectrum.

While polymeter and polyrhythm have many similarities, the examples also suggest that each has expressive and compositional potential unique to each. With polymeter, intricacies of time between the beat become more apparent, as seen in the complexity of the lines between the strong beats in the Rite of Spring example. This kind of peculiarity becomes difficult to discern if it were to take place in the time between beats of a simple polyrhythm.

This should not detract from the merit of polyrhythms, however. As polyrhythms take place over a shorter amount of time, discerning the structure as a whole is easier. With largescale examples, such as the one from Three Places in New England, it often takes trained ears to discern the individual meters and their relationships. In clear, concise polyrhythmic structures, such as the ones found in Britten's Nocturnal, the 3:2 relationships are clearly heard even by untrained listeners.

Suffice to say, both forms of divisive dissonances have advantages over one another depending on the compositional situation.

\subsection{Polytempo}

As stated previously, the frequency of alignment points within a specific texture serves as the distinction between polytempo and complex polyrhythms. The following examples demonstrate occurrences of polytemporal structures through a variety of notational practices. The following is an excerpt from The Rite of Spring. For the sake of brevity, only the necessary passages are shown below.

At 10, the contrabassoons and the sixth contrabass maintain a figure that is notated as a triplet. This triplet figure is phrased in groups of four eighth-note triplets, which does not match the cardinality of the tuplet. While its notation suggests a complex polyrhythm, this figure acts as a polytemporal one. Observing the rest of the texture, no alignment points appear for some time. The other voices occur on off beats and contain many tuplets themselves, while still expressing the strong beats of the meter as an aggregate. This creates rhythmic dissonance between the triplet voices and the others.

The dissonance never truly resolves, as no alignment points occur during the duration of this texture. The texture simply ceases at 12 and moves on to new material. Stravinsky creates rhythmic tension and denies the release to the listener. The lack of alignment points, and convergence points, suggest a polytemporal structure over a polyrhythmic structure, thus I 


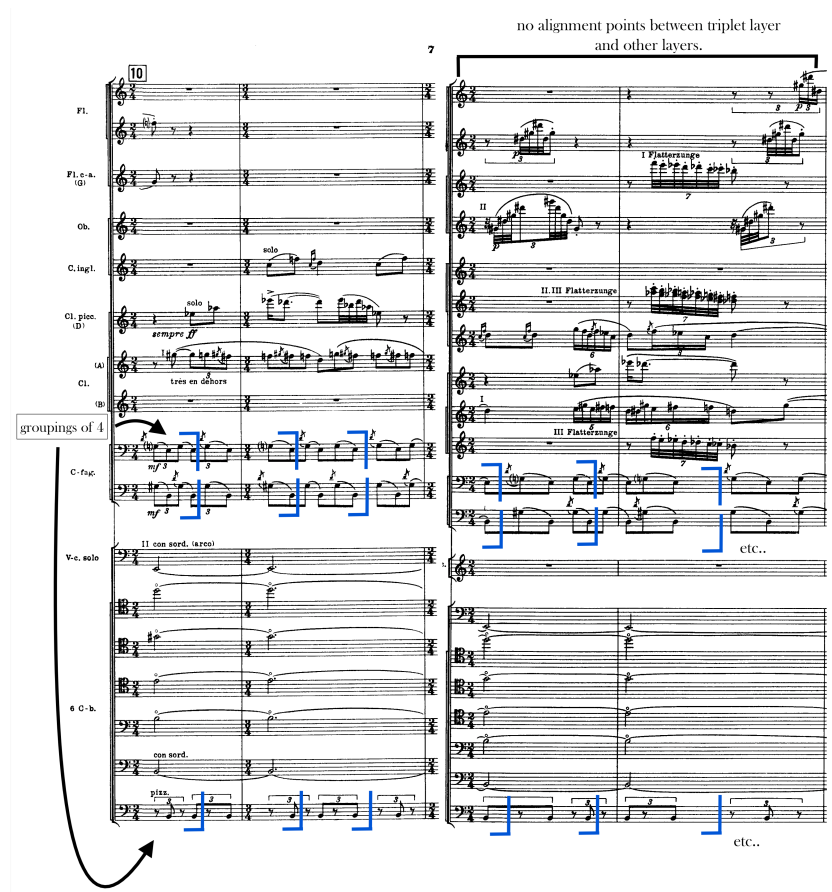

Figure 21. Igor Stravinsky: The Rite of Spring,

"Introduction"

am interpreting this section as having two tempo streams with one moving at 1.5 times the speed of the other.

While all of the works I have presented thus far have come from the 20th century or later, rhythmic dissonance is not a wholly new phenomenon. The following comes from Johannes Ockeghem's mass, Missa Prolationum. The mass consists of a multitude of prolation canons, which are polytemporal structures. The opening of the Kyrie clearly shows these canons in context. ${ }^{51}$

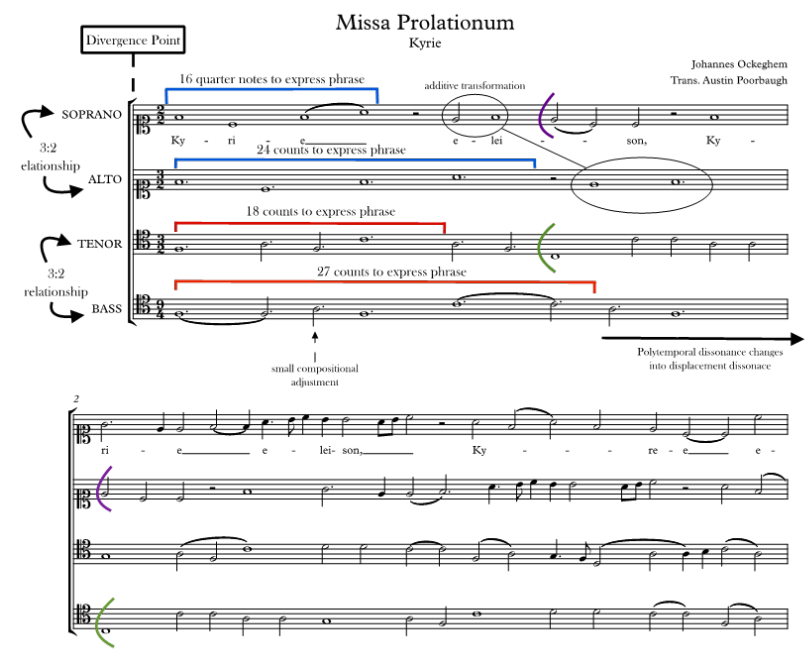

Figure 22. Johannes Ockeghem: Missa Prolationum, "Kyrie"

\footnotetext{
${ }^{51}$ Ockeghem, Johannes, Missa Prolationum, Copyright (C) 1966, American Musicological Society Inc, All rights reserved, Used by permission, trans. by Austin Poorbaugh.
}

The last example is a graphic representation of Conlon Nancarrows Player Piano Study No. 21. This piece contains two voices of differing tempos which are also under constant manipulation, with the upper voice in a constant accelerando and the lower voice in a constant ritardando. ${ }^{52}$

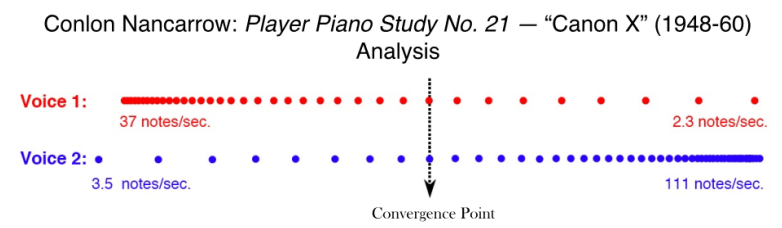

Figure 23. Analysis of Conlon Nancarrow's Player Piano Study No. 21

The initial ratio relationship of 74:7 is quite complex. As the tempos change the ratio begins to approach 1:1. The only convergence point of the piece occurs at this moment. As time continues, this moment becomes a divergence point and the two voices begin to morph into a ratio of 1110:23. The difference in tempi between the two voices at the beginning and end are so extreme that the lines are not heard in relation to another. Rather, the effect is that of two seperate entities, as the voices do not begin to aurally intertwine until they approach the convergence point.

The climax of the piece occurs at the convergence point. The extreme temporal dissonances at either end of the time spectrum serve to drive the listener both towards and away from this climatic moment. As the lines accelerate or ritard, they pass through several different dissonant states, creating tension. The release comes from the brief moment of consonance at the 1:1 point. Following this moment, the voices begin to diverge once more and drift back into increasing dissonance.

\subsection{Contextual}

Contextual dissonance analysis closely resembles that of divisive dissonances. However, ratio relationships are determined through horizontal analysis rather than vertical. In the following discussion, I will focus on examples of periodic and non-periodic dissonances.

The following example uses periodicity and metric extensions. On the contextual spectrum, this piece is mostly asymmetrically periodic with at least two variants of beat groupings. Mackey will quite often develop these periodic cells by morphing them into an elongated line or interrupting and combining them with other cells, while maintaining the key relationships between these cells. ${ }^{53}$

In the above example $\mathrm{G}$ contains an initial period with a 7:4 ratio relationship. This relatively unstable period is developed through various prolongations and a brief periodic

\footnotetext{
${ }^{52}$ Klein, Joseph, "Explorations in Time: Rhythm, Meter, and Tempo," MUCP 1190 Lectures, 2015.

${ }^{53}$ Mackey, John, Wine-Dark Sea: Symphony for Band (OstiMusic, Inc., 2014), Used by permission.
} 
Metric Reduction of Hubris, from Wine Dark Sea $\mathrm{G} \mathrm{to} \mathrm{K}$
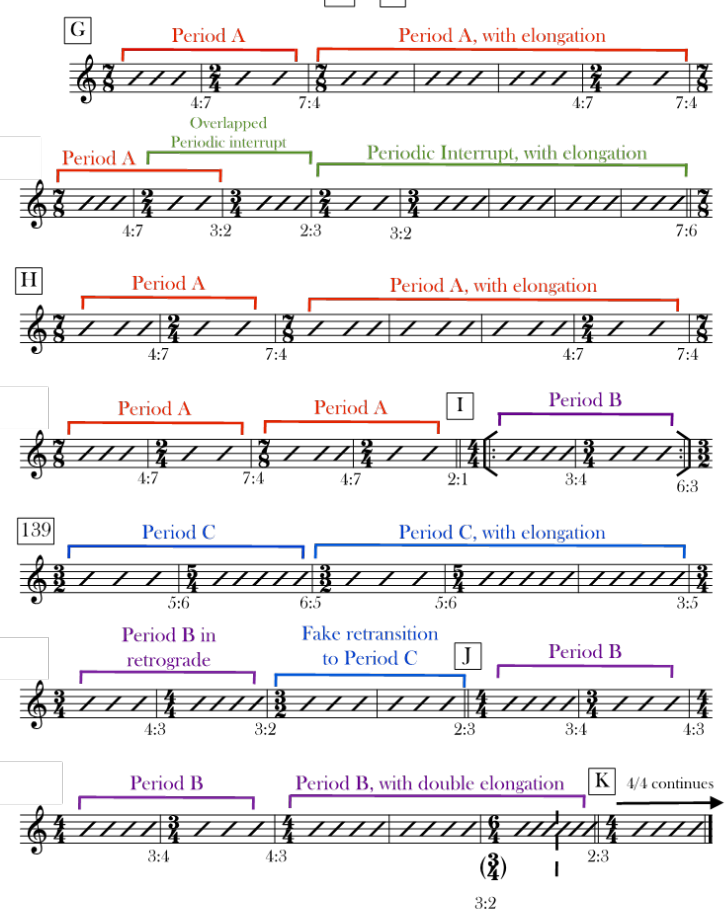

Figure 24. John Mackey: Wine Dark Sea, "Hubris"

interruption whose ratio relationship is much more stable at $3: 2$. This section leads into I, which has a weaker degree of dissonance with its truly periodic 3:4 relationship.

Beginning at measure 139, a new periodic cycle with a ratio relationship of 5:6 is introduced. This new period is developed with elongations, interruptions of previous periods, and false retransitions. At J, the period from I returns for two cycles and a double prolongation, and takes the music into $\mathrm{K}$, which is comprised of a stable, periodic 4/4. The Mackey example shows how a single periodic idea can be developed and transformed through the use of prolongation, interruption, and shifts from consonant to relatively dissonant rhythmic cycles.

Elliott Carter's timpani piece, "Canaries" from Eight Pieces for Four Timpani, illustrates several interesting phenomena that arise from the temporal relationships inherent in the microlevel. When making a microlevel rhythmic translation, the only pitches present initially are those within a dominant 7 th chord of the primary subdivision. (In the example below, the dotted quarter note will be represented harmonically as F2.) Within a texture of various beat divisions, the cardinality of each division will correspond to a partial of the overtone series, while the primary beat will always correspond to the fundamental. For example, the primary beat divided in two will correspond to the second partial of the overtone series, divided into three it will correspond to the third, and so on.
This relationship exists as a result of the ratio relationships between various beat divisions that, as discussed previously, are identical to those found in the overtone series. ${ }^{54}$
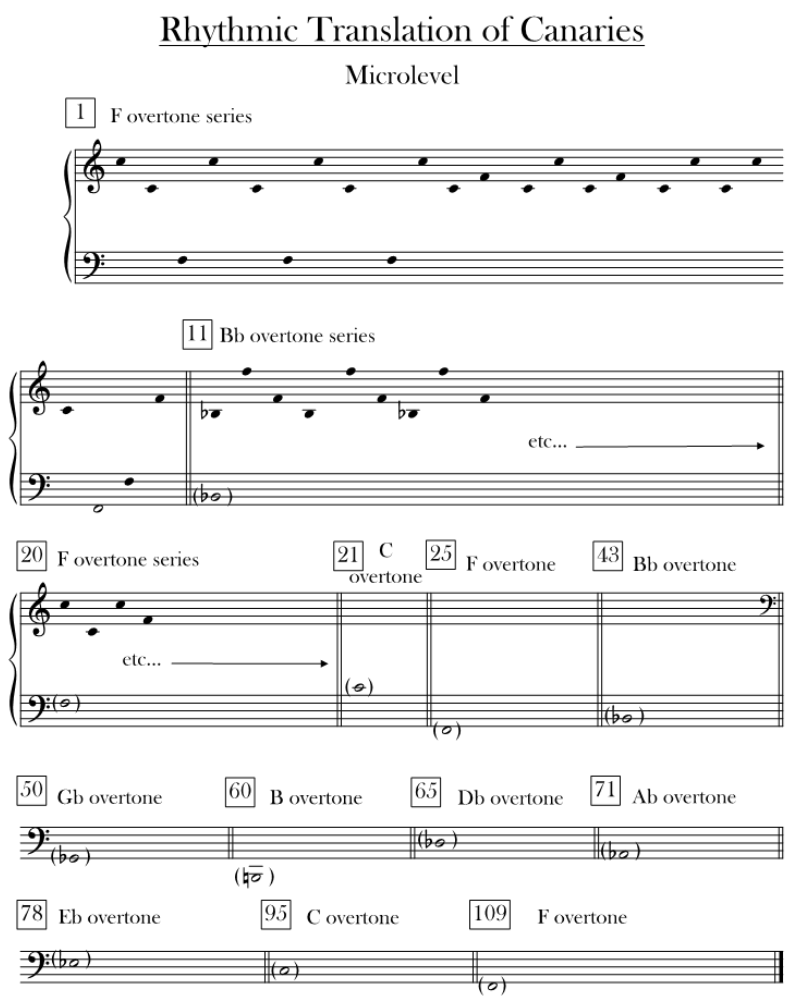

Figure 25. Elliott Carter: Eight Pieces for Four Timpani, "Canaries"

To take the overtone series comparison a step further, consider the primary beat division as the fundamental pitch of an overtone series. Different divisions of that beat will correspond to different partials of the overtone series. When a metric modulation changes the duration of a primary beat or its tempo, this new total duration becomes the new fundamental and divisions of this beat will yield a different set of overtones in relation to the initial tempo or beat division. Thus, one can conceptualize changes of tempo as a change of key or a change in the home overtone series. Here the contextual dissonance arises from the variations of horizontal tempi.

"Canaries" travels through several different tempos and, by extension, several different overtone series. The analysis makes note of these overtone series, and demonstrates the viability of metric modulation and temporal relationships as tools to create and resolve rhythmic dissonance. Only the microlevel analysis is shown below. The analysis begins by showing every interval present between the beat divisions, but eventually only shows the overtone series. This is because the intervals present are nearly all within the dominant 7 th chord of the root note. For the sake of brevity this information has

\footnotetext{
${ }^{54}$ EIGHT PIECES FOR FOUR TIMPANI, Music by Elliott Carter Copyright (C) 1968 (Renewed) by Associated Music Publishers, Inc.(BMI) International Copyright Secured. All Rights Reserved.
} 
been omitted, as the focus is the overall relationships between the successive tempi.

\section{Explanation of Canaries Translation}

\begin{tabular}{ccc} 
Measure \# & Tempo & $\begin{array}{c}\text { Ratio } \\
\text { Relationship to } \\
\text { initial tempo }\end{array}$ \\
\hline 1 & 90 & $1: 1$ (mitial tempo) \\
\hline 11 & 120 & $4: 3$ (P4 above) \\
\hline 20 & 180 & $2: 1$ (octave albove) \\
\hline 21 & 270 & $3: 1$ (octave + P5 above) \\
\hline 25 & 90 & $1: 1$ (mitial tenno) \\
\hline 43 & 120 & $4: 3$ (P4 above) \\
\hline 50 & 96 & $16: 15$ (m2 above) \\
\hline 60 & 64 & $32: 45$ (tritone below) \\
\hline 65 & 144 & $8: 5$ (m6 above) \\
\hline 71 & 108 & $6: 5$ (m3 above) \\
\hline 78 & 162 & $9: 5$ (m7 above) \\
\hline 95 & 135 & $3: 2$ (P5 albove) \\
\hline 109 & 90 & $1: 1$ (return to initial) \\
\hline
\end{tabular}

Figure 26. "Canaries" Explanation

\section{Conclusions}

The previous sections of this paper have presented the background, an organizational system, and compositional examples of rhythmic dissonance in the music literature. Through a careful analysis of the compositional examples, several approaches to application of these procedures present themselves. The most obvious of these is the usage of rhythmic dissonance in the same way harmonic dissonance is utilized in tonal music: i.e., as a way of guiding the listener through a tension and release scheme. The degrees of dissonance provide a quantifiable order of tensions that can be equated to a tonic, subdominant, and dominant progression.

Rhythmic dissonance allows for alternate avenues in the development of a single idea. The Mackey example takes simple periodic sequences and interrupts and overlaps them to decrease the degree of predictability. Cowell uses the most dissonant texture to emphasize the climax of Fabric. Britten used a polyrhythmic figure as the central idea to be developed, increasing the tension and displacing the figure at various points in the excerpt. These all provide options to make a work more interesting and effective.

Rhythmic dissonance has the advantage of coming to prominence after the historic trials of tonal harmonic concepts have been thoroughly tested. This means that, while I have presented several systems with inherent organizational schemes, there is no expectation of following any set of rules as composers apply these techniques in the future. This is evident after reviewing examples from the literature, such as the Stravinsky excerpt that "resolves" the tension through silence, or the polytemporal Stravinsky example that simply ends without any resolution. The Furrer example maintains a dissonant texture throughout, which, in context, becomes the median texture; since there is no objectively consonant material present the listener's ear accepts the dissonant texture as the norm in context. This is analogous to atonal music, where what has historically been considered dissonant harmony becomes the norm. Also, the techniques and phenomena in this paper may be disregarded entirely, as is the case in spatially notated music.

Overall, rhythmic dissonance provides the composer with ample opportunity to augment their current compositional ideas with new avenues of development.

\section{Final Thoughts}

Currently, the fields of music theory and music composition painfully neglect the potential of rhythmic dissonance as a viable method of analysis and as a compositional tool. Evidence has shown that composers of the present and past, whether consciously or not, have utilized rhythmic figures and their subsequent variation/dissolution as a form of compositional development and expressive potential. The next phase involves supplying the composers of the future with the tools and ideas necessary to consciously and intelligently utilize these rhythmic processes, which I have collectively labeled as rhythmic dissonances, in their work. In this way, future generations of composers may exploit these processes and create works that build upon those that have come before. The contents of this paper provide the first steps of this initiative. It is through directly confronting issues regarding rhythm and rhythmic dissonance that music will continue to develop in this regard.

However, it is important for the author to state that the material discussed within this paper is not presented in the hopes of creating a prescriptive system of application; rather, that the awareness of this material's existence and the plausible interest in its development will inspire and encourage composers of the current time to explore all rhythmic possibilities available in the future. Music requires continuous experimentation and exploration in order to maintain its ongoing forward momentum. The acceptance of rhythmic dissonance within the music community is just one piece of this multifaceted puzzle.

\section{Author Biography}

Evan O. Adams is a composer and dance musician currently based in Denton, Texas. Adams will graduate with honors in May 2018 for the University of North Texas, where he has studied composition with Dr. Andrew May and Claudia 
Howard Queen, and guitar with Thomas Johnson and Stephen Lochbaum. He currently works as a dance musician for UNT's Department of Dance and Theatre, under the tutelage of Claudia Queen. In 2017 he, along with four other composers, founded Eclective, an eclectic new art collective dedicated to stylistic diversity and cross-medium collaborations. Serving as Artistic Director, he has overseen and composed music for several projects incorporating film, music, dance, and theatre. In addition to creative work, Adams also has an interest in musical research, exploring topics such as Rhythmic Dissonance and semitone modulations in 16th century vocal works. 